\title{
DISPENSAS DE LICITAÇÃO DURANTE A COVID-19: COMO OS ESTADOS BRASILEIROS MOTIVAM SUAS DECISÕES?
}

\author{
DANIEL BARCELOS VARGAS ${ }^{1}$ \\ BEATRIZ GUIMARÃES MENEZES ${ }^{2}$ \\ ISA MOTA RANGEL ${ }^{3}$
}

RESUMO: Este artigo propõe uma análise empírica dos processos de dispensa de licitação, no cenário da pandemia causada pela COVID-19, nos vinte e seis estados da federação e no Distrito Federal. $\mathrm{O}$ objetivo é identificar se gestores públicos cumprem os requisitos legais previstos para a realização das compras diretas, de forma a possibilitar o controle dos atos administrativos por parte da população e, sobretudo, pelos órgãos de controle. $\mathrm{O}$ artigo também sugerirá que a fragilidade das justificativas para dispensa de licitação pode estar por trás de tensão constante entre gestores públicos e controladores no país.

Palavras-Chave: Dispensa de Licitação; COVID-19; Pesquisa Empírica.

\footnotetext{
1 Professor da Fundação Getúlio Vargas - FGV Direito Rio. Doutor (2014) e Mestre (2006) em Direito pela Universidade de Harvard. Mestre (2005) e Bacharel (2003) em Direito pela Universidade de Brasília.

2 Estudante do Curso de Direito da Fundação Getúlio Vargas - FGV Direito Rio.

${ }^{3}$ Estudante do Curso de Direito da Fundação Getúlio Vargas - FGV Direito Rio.
} 
1. Introdução 128

2. Dispensa de licitação 129

$\begin{array}{ll}\text { 2.1. Nova modalidade } & 130\end{array}$

2.2. Justificativa de dispensa $\quad 131$

3. Relatório dos Estados 134

$\begin{array}{ll}\text { 3.1. Norte } & 135\end{array}$

3.1.1. Acre 135

3.1.2. Amapá 137

3.1.3. Amazonas 138

3.1.4. Pará 139

3.1.5. Rondônia 141

3.1.6. Roraima 143

3.1.7. Tocantins 144

3.2. Nordeste $\quad \mathbf{1 4 4}$

3.2.1. Alagoas 144

3.2.2. Bahia 145

3.2.3. Ceará 146

3.2.4. Maranhão 147

3.2.5. Paraíba 148

3.2.6. Pernambuco 149

3.2.7. Piauí 149

3.2.8. Rio Grande do Norte 152

3.2.9. Sergipe 152

3.3. Centro-Oeste 153

3.3.1. Distrito Federal 153

3.3.2. Goiás 154

3.3.3. Mato Grosso 154

3.3.4. Mato Grosso do Sul 155

3.4. Sudeste 156

3.4.1. Espírito Santo 156

3.4.2. Minas Gerais 157

3.4.3. Rio de Janeiro 157

3.4.4. São Paulo 158

3.5. Sul 160

3.5.1. Paraná 160

3.5.2. Rio Grande do Sul 160

3.5.3. Santa Catarina 161

4. Análise 161

5. Conclusão 164 


\section{INTRODUÇÃO}

Em março de 2020, a Organização Mundial da Saúde (OMS) conferiu o status de pandemia à Covid-19. A síndrome respiratória com altos índices de transmissão e, em casos mais graves, risco real de morte, tornou-se uma preocupação em todo o mundo. A rápida disseminação do vírus demandou a adoção de diversas medidas de prevenção como o lockdown, distanciamento social, adoção de máscaras faciais e uso frequente de higienizadores como o álcool em gel.

O combate, contudo, não se restringiu à sanitização, mas repercutiu em diversas áreas, como o direito administrativo. A Lei Federal $n^{\circ}$ 13.979/2020 4, também conhecida como "Lei do Coronavírus", buscou agilizar o processo de compras e aquisições para prover os itens necessários ao combate à pandemia. Para isso, entre outras previsões, a lei instituiu nova modalidade de dispensa de licitação para compras e aquisições durante a pandemia. Desde então, as dispensas, normalmente uma exceção no direito administrativo, têm se multiplicado pelos estados da federação.

Com o aumento das dispensas de licitação, também ascenderam no Brasil os termos de uma tensão já conhecida no país. De um lado, órgãos de controle levantam dúvidas sobre a boa aplicação dos recursos públicos. A pandemia nem acabou e os escândalos de fraudes e desvios de verbas já chamam a atenção nacional. ${ }^{5}$ De outro lado, gestores receosos de serem as próximas vítimas de uma operação histriônica dos controladores reagem cruzando os braços, com receio de realizar novas compras emergenciais.

A disputa entre os lados é carregada de presunções. Para os gestores públicos, os controladores ignoram a realidade dura da administração pública estadual durante a pandemia, premida pela emergência, pelo mercado rarefeito e pela urgência em agir para salvar vidas. Para os controladores, por sua vez, a emergência de saúde pública não é nem pode ser uma licença para corrupção e desmandos com dinheiro público, que há tanto tempo magoam a credibilidade do estado brasileiro.

Na disputa entre desconfianças, quem sai perdendo é o país.

\footnotetext{
${ }^{4}$ BRASIL. Lei 13.979 de 06 de fevereiro de 2020. Presidência da República Casa Civil, 2020. Disponível em: <http://www.planalto.gov.br/ccivil_03/leis/18666cons.htm>. Acesso em: $01 \mathrm{de}$ agosto de 2020.

${ }^{5}$ Casos emblemáticos, em estados como Rio de Janeiro e Pará, incluem os seguintes.

MINISTÉRIO PÚBLICO DO RIO DE JANEIRO. MPRJ realiza operação em investigação sobre contratos de aquisição de respiradores em meio à pandemia do novo coronavírus, 2020. Disponível em: <https://www.mprj.mp.br/home/-/detalhe-noticia/visualizar/84918> Acesso em: 06 de outubro de 2020.

POLÍCIA FEDERAL. MINISTÉRIO DA JUSTIÇA E SEGURANÇA PÚBLICA. Polícia Federal deflagra Operação Para Bellum e investiga compra de respiradores no Pará, 2020. Disponível em: $<$ http://www.pf.gov.br/imprensa/noticias/2020/06-noticias-de-junho-de-2020/policia-federaldeflagra-operacao-para-bellum-e-investiga-compra-de-respiradores-no-para $>$ Acesso em: 06 de outubro de 2020.
} 


\section{Quem tem razão nesta briga?}

O artigo pretende sugerir que "nenhum dos lados". Ou melhor, esperamos argumentar que existe um outro problema por trás desta briga, ainda pouco compreendido, mas tão ou mais decisivo para resolver a pendenga nacional. O que parece estar ocorrendo no país, em grande medida, é a ausência básica de justificação das decisões administrativas de dispensar a licitação para compras. Justificar não é apenas relatar um fato, tampouco mencionar uma lei, mas é, sobretudo, conectar as duas pontas: argumentar porque, no caso em particular, a compra pública deve ser realizada segundo determinado critério legal.

Sem a justificação do ato administrativo, o que parece se seguir é um "diálogo de surdos". O controlador, sem dados ou motivação básica disponível no processo de dispensa, mas premido por sua atribuição de zelar pela proteção do bem público, passa a desconfiar e questionar o que pode estar por trás de gastos que não obedecem aos padrões legais. O gestor, por sua vez, sentindo-se ameaçado e injustiçado pela desconfiança permanente do controlador, reage com igual desconfiança e com mais receio de assumir atribuição que envolva dispêndio de recursos.

O círculo de desconfianças recíprocas ameaça "minar" o papel do direito como meio de campo da interação entre os órgãos do estado.

A caracterização deste "problema de fundo" na relação entre gestores e fiscais é, antes de mais nada, uma tarefa empírica. O desafio principal consiste em revelar como os gestores públicos, em cada um dos estados da federação, têm utilizado o instrumento da dispensa de licitação durante a pandemia. Para isso, conduzimos análise empírica compreensiva dos processos de dispensa licitatória disponibilizados nas bases públicas dos estados brasileiros. Consolidamos as informações em uma base comum, que revela o perfil das decisões tomadas pelos gestores públicos no país. A análise constata que as dispensas de licitação têm justificativas precárias. Sem dados ou argumentos consistentes, o que deveria ser um diálogo interinstitucional entre gestores e fiscais, mediado pelo direito, tende a se converter em uma luta porosa de preconceitos.

$\mathrm{O}$ artigo se estrutura em três partes.

$\mathrm{Na}$ primeira, apresentamos o conjunto legal que disciplina a dispensa de licitação durante a pandemia e traça os elementos mínimos para uma motivação do ato. Em seguida, examinamos os processos de compras disponíveis em bases públicas em cada um dos estados da federação em um período delimitado. Casos exemplares ajudam a compreender a realidade em cada estado. Finalmente, sistematizamos os dados em base comum e interpretamos o resultado.

\section{DISPENSA DE LICITAÇÃO}

A licitação é o procedimento pelo qual, em regra, a administração pública realiza suas contratações ${ }^{6}$. Trata-se de "procedimento administrativo disciplinado

\footnotetext{
${ }^{6}$ BRASIL. Lei 8.666 de 21 de junho de 1993. Presidência da República Casa Civil, 1993. Disponível em: <http://www.planalto.gov.br/ccivil_03/leis/18666cons.htm>. Acesso em: 01 de agosto de 2020;
} 
por lei e por um ato administrativo prévio, que determina critérios objetivos de seleção da proposta de contratação mais vantajosa, com observância do princípio da isonomia, conduzido por um órgão dotado de competência específica" ${ }^{7}$

Embora a licitação seja a regra, há casos excepcionais em que tal procedimento não é capaz de atender aos próprios objetivos a que se dispõe. Para essas circunstâncias, a própria lei autoriza a contratação direta por meio de dispensa ou inexigibilidade de licitação. ${ }^{8}$ A dispensa de licitação, em outras palavras, é uma autorização para que o rito ordinário da licitação seja afastado em casos especiais.

\subsection{Nova modalidade}

Em 30 de janeiro de 2020, a Organização Mundial da Saúde declarou a infecção humana pelo novo Coronavírus como Emergência em Saúde Pública de Importância Internacional. No Brasil, a Portaria ${ }^{\circ}$ 188/GM/MS, de 4 de fevereiro de $2020^{\circ}$, declarou Emergência em Saúde Pública de Importância Nacional. Desde a confirmação do primeiro caso de contaminação no país, em 26 de fevereiro de 2020, foram adotadas diversas medidas sanitárias, financeiras e administrativas para conter seu avanço.

A Lei n ${ }^{\circ} 13.979$, de 6 de fevereiro de 2020 (“Lei do Coronavírus"), ${ }^{10}$ estabelece uma série de medidas para enfrentamento emergencial da Covid-19. Entre elas, cria uma nova hipótese de dispensa de licitação para itens destinados a combater a Emergência Internacional. Esta é a disciplina do artigo $4^{\circ}$ da nova lei:

“Art. $4^{\mathrm{o}}$ Fica dispensada a licitação para aquisição de bens, serviços e insumos de saúde destinados ao enfrentamento da emergência de saúde pública de importância internacional decorrente do coronavírus de que trata esta Lei."

Posteriormente, a Medida Provisória n 926, de 20 de março de 2020 11, alterou a Lei $\mathrm{n}^{\circ} 13.979$ de 2020, e o referido artigo passou a vigorar nos seguintes termos:

BRASIL. Lei 13.979 de 06 de fevereiro de 2020. Presidência da República Casa Civil, 2020. Disponível em: <http://www.planalto.gov.br/ccivil_03/leis/18666cons.htm>. Acesso em: 01 de agosto de 2020.

7 FILHO, Marçal Justen. Curso de Direito Administrativo. São Paulo: Editora Saraiva, 2005, p.309.

8 BRASIL. Lei 8.666 de 21 de junho de 1993. Presidência da República Casa Civil, 1993. Artigo 24. Disponível em: <http://www.planalto.gov.br/ccivil_03/leis/18666cons.htm>. Acesso em: $01 \mathrm{de}$ agosto de 2020.

${ }^{9}$ BRASIL. Portaria n ${ }^{\circ}$ 188/GM/MS, de 4 de fevereiro de 2020. Diário Oficial da União. Disponível em: < https://www.in.gov.br/en/web/dou/-/portaria-n-188-de-3-de-fevereiro-de-2020-241408388>. Acesso em: 01 de agosto de 2020.

${ }^{10}$ BRASIL. Lei 13.979 de 06 de fevereiro de 2020. Presidência da República Casa Civil, 2020. Disponível em: <http://www.planalto.gov.br/ccivil_03/leis/18666cons.htm>. Acesso em: 01 de agosto de 2020.

${ }^{11}$ BRASIL. Medida Provisória n ${ }^{\circ}$ 926, de 20 de março de 2020. Presidência da República Secretaria Geral Subchefia de Assuntos Jurídicos. Disponível em: < 


\begin{abstract}
“Art. 4ํㅡ É dispensável a licitação para aquisição de bens, serviços, inclusive de engenharia, e insumos destinados ao enfrentamento da emergência de saúde pública de importância internacional decorrente do coronavírus de que trata esta Lei."
\end{abstract}

No rastro do governo federal, vários estados também editaram suas próprias normas para reforçar o procedimento acelerado de contratação, com dispensa licitatória. A proliferação de novas regras para não é por acaso. $\mathrm{O}$ rigor e as formalidades do procedimento de compra são essenciais para assegurar o bom uso do dinheiro público e resguardar o administrador contra eventual responsabilização. A realização de procedimentos de compra ordinários, contudo, podem se prolongar por meses, ameaçando a paralisia do atendimento à população. O combate aos efeitos da pandemia exige celeridade excepcional nas compras públicas.

\title{
2.2. Justificativa de dispensa
}

A criação de nova modalidade de dispensa licitatória não significa uma licença indiscriminada para administrador comprar o que quiser e como bem entender. A fundamentação da dispensa de licitação exige a demonstração de alguns elementos básicos, ou seja, padrões mínimos de justificação, ${ }^{12}$ que incluam (1) uma base normativa, (2) uma circunstância fática, e (3) uma conexão entre a norma e o fatoé dizer, a demonstração de um elo mínimo de entre os elementos anteriores.

Em cada área da administração, estes três elementos podem ter caracterizações diversas. Na compra de bens para atender às demandas da pandemia, a Lei de Licitações e a Lei do Coronavírus fixam os critérios básicos para a dispensa. $\mathrm{O}$ conjunto geral dos elementos da justificativa de dispensa estão previstos no parágrafo único do artigo 26 da Lei de Licitações. Confira:

\footnotetext{
“Art. 26, Parágrafo único. O processo de dispensa, de inexigibilidade ou de retardamento, previsto neste artigo, será instruído, no que couber, com os seguintes elementos:
}

\footnotetext{
http://www.planalto.gov.br/ccivil_03/_ato2019-2022/2020/Mpv/mpv926.htmAcesso em: 01 de agosto de 2020.

${ }^{12} \mathrm{O}$ artigo 26, parágrafo único, da Lei 8.666 de 1993, dispõe sobre alguns destes elementos básicos: "O processo de dispensa, de inexigibilidade ou de retardamento, previsto neste artigo, será instruído, no que couber, com os seguintes elementos: I - caracterização da situação emergencial, calamitosa ou de grave e iminente risco à segurança pública que justifique a dispensa, quando for o caso; II - razão da escolha do fornecedor ou executante; III - justificativa do preço; IV - documento de aprovação dos projetos de pesquisa aos quais os bens serão alocados." (Lei 8.666/93).

BRASIL. Lei 8.666 de 21 de junho de 1993. Presidência da República Casa Civil, 1993. Disponível em: $<$ http://www.planalto.gov.br/ccivil_03/leis/18666cons.htm>. Acesso em: 01 de agosto de 2020.
} 
I - caracterização da situação emergencial, calamitosa ou de grave e iminente risco à segurança pública que justifique a dispensa, quando for o caso;

II - razão da escolha do fornecedor ou executante;

III - justificativa do preço;

$I V$ - documento de aprovação dos projetos de pesquisa aos quais os bens serão alocados." (Lei 8.666/93).

A Lei do Coronavírus flexibiliza as exigências da Lei de Licitação, para responder às urgências da contratação durante a pandemia. Faz isso criando, em primeiro lugar, uma presunção de legalidade quanto aos fatos e circunstâncias básicas que orientam a decisão do gestor. Veja o disposto em seu art. $4^{\circ}$ - B da Lei do Coronavírus:

Art. 4⿳⺈-B Nas dispensas de licitação decorrentes do disposto nesta Lei, presumem-se atendidas as condições de:

I - ocorrência de situação de emergência;

II - necessidade de pronto atendimento da situação de emergência;

III - existência de risco a segurança de pessoas, obras, prestação de serviços, equipamentos e outros bens, públicos ou particulares; $e$ IV - limitação da contratação à parcela necessária ao atendimento da situação de emergência.

Esta presunção de legalidade é uma "proteção" especial ao gestor público e uma orientação ao controlador. Na decisão de dispensa, presume-se a emergência, a necessidade de pronto atendimento, risco a pessoas e bens e aos limites necessários para atendimento à situação de emergência. Salvo comprovação de abuso mediante dolo ou erro grosseiro, o gestor está, em regra, protegido contra eventuais questionamentos. ${ }^{13}$

O significado exato desse dispositivo, contudo, precisa ser compreendido com cuidado.

Primeiro, o artigo $4^{\circ}$-B reduz o escopo de aplicação da regra geral do inciso I, parágrafo único, do artigo 26 da Lei de Licitações. A "emergência" e o "risco" no país são presumidos. Mas a norma não elimina o dever do gestor de fundamentar em particular a sua decisão, nem retira a responsabilidade do controlador de aferir, em momento seguinte, os critérios de execução dos gastos. $\mathrm{O}$ princípio geral da motivação dos atos administrativos continua em vigor, assim como a exigência do artigo 50, inciso IV, da Lei 9.789 de $1999^{14}$. Confira:

\footnotetext{
${ }^{13}$ Art. 28 do Decreto-Lei no. 4.657, de 1942, alterado pela Lei no. 13.655, de 2018.

${ }^{14}$ BRASIL. Lei 9.789 de 29 de janeiro de 1999. Presidência da República Casa Civil, 1999. Disponível em: <http://www.planalto.gov.br/ccivil_03/leis/19784.htm>. Acesso em: 01 de agosto de 2020.
} 
Art. 50. Os atos administrativos deverão ser motivados, com indicação dos fatos e dos fundamentos jurídicos, quando: (...)

IV - dispensem ou declarem a inexigibilidade de processo licitatório;

Segundo o conjunto de elementos básicos da dispensa, na Lei de Licitações, é significativamente mais amplo do que a flexibilização da Lei do Coronavírus. A presunção de emergência, urgência e risco não é, por si só, suficiente para demonstrar outras características essenciais à decisão de dispensa licitatória do gestor público durante a pandemia. ${ }^{15}$

Terceiro, a presunção de legalidade do ato do gestor público não é absoluta. Afinal, a crise é nacional, mas atinge estados e regiões em ritmos diferentes. As carências e urgências em cada parte do país não se dão todas ao mesmo tempo, necessariamente. Justamente por isso, a presunção legal não elimina a tarefa do gestor de esclarecer minimamente as suas circunstâncias particulares.

Essas particularidades da justificação da dispensa de licitação no combate à Covid-19 detalham os elementos básicos de uma decisão administrativa adequada. No mínimo, tal decisão deve conter: (1) base normativa clara, (2) circunstância fática, e (3) conexão entre a norma e o fato-é dizer, a demonstração de um elo mínimo de entre os elementos anteriores.

\section{a. Ato normativo}

A possibilidade de dispensa de licitação deve estar prevista em lei. O gestor não é obrigado a mencionar o dispositivo legal em sua decisão. Presume-se o conhecimento da norma no direito. Porém, na justificação de sua decisão, é comum a referência à norma inclusive para esclarecer como o caso concreto se insere no quadro normativo vigente. As fundamentações legais mais comuns são a Lei

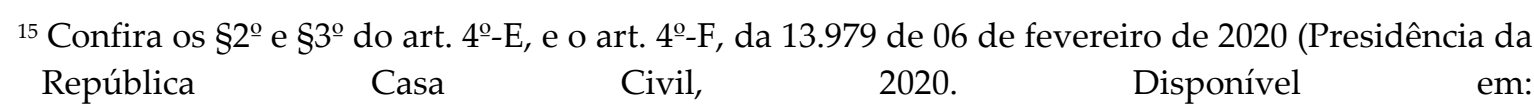
$<$ http://www.planalto.gov.br/ccivil_03/leis/18666cons.htm>. Acesso em: 01 de agosto de 2020).

$\S 2^{\mathrm{o}}$ Excepcionalmente, mediante justificativa da autoridade competente, será dispensada a estimativa de preços de que trata o inciso VI do $\S 1^{\circ}$ deste artigo.

$\S 3^{o}$ Os preços obtidos a partir da estimativa de que trata o inciso VI do $\S 1^{\circ}$ deste artigo não impedem a contratação pelo poder público por valores superiores decorrentes de oscilações ocasionadas pela variação de preços, desde que observadas as seguintes condições:

I - negociação prévia com os demais fornecedores, segundo a ordem de classificação, para obtenção de condições mais vantajosas; e

II - efetiva fundamentação, nos autos da contratação correspondente, da variação de preços praticados no mercado por motivo superveniente.

Art. $4^{\circ}$-F. Na hipótese de haver restrição de fornecedores ou de prestadores de serviço, a autoridade competente, excepcionalmente e mediante justificativa, poderá dispensar a apresentação de documentação relativa à regularidade fiscal ou, ainda, o cumprimento de 1 (um) ou mais requisitos de habilitação, ressalvados a exigência de apresentação de prova de regularidade trabalhista e o cumprimento do disposto no inciso XXXIII do caput do art. $7^{0}$ da Constituição Federal. 
13.979/2020 ${ }^{16}$, a Lei 8.666/93 ${ }^{17}$ e a MP 926/2020 $0^{18}$. Há também previsões legais de origem estadual que qualificam o processo licitatório.

\section{b. Circunstância}

A dispensa de licitação deve explicitar a realidade em que ocorre a compra pública. Não basta que a exposição dos fatos seja genérica ou abstrata-embora, em linhas gerais, se presuma a emergência e a urgência da contratação. Aqui se incluem elementos definidos nos incisos do artigo 26 da Lei 8.666 de $1993{ }^{19}$, como a razão da escolha do fornecedor ou executante; preços; documentos de aprovação dos projetos de pesquisa aos quais os bens serão alocados, com as flexibilizações admitidas pela Lei do Coronavírus.

\section{c. Nexo}

A dispensa de licitação deve explicitar a relação entre a norma e o fato; é dizer, oferecer uma justificativa de sua decisão, em sentido estrito. Cabe ao gestor demonstrar que a situação concreta realmente se encaixa no quadro normativo em vigor e, portanto, a dispensa de licitação é adequada para a contratação pública. A relação entre o mundo fático e o mundo normativo, por assim dizer, deve ser minimamente desenvolvida a partir de argumentações particulares e específicas.

\section{RELATÓRIO DOS ESTADOS}

A pesquisa utilizou como base de estudo os 26 estados e o Distrito Federal no período de 17 de agosto de 2020 a 7 de setembro de 2020. No levantamento dos dados, foram examinados todos os processos de dispensa de licitação disponíveis nas bases públicas dos estados. ${ }^{20}$ Vários processos, contudo, ainda não estavam

16 BRASIL. Lei 13.979 de 06 de fevereiro de 2020. Presidência da República Casa Civil, 2020. Disponível em: <http://www.planalto.gov.br/ccivil_03/leis/18666cons.htm>. Acesso em: 01 de agosto de 2020.

${ }^{17}$ BRASIL. Lei 8.666 de 21 de junho de 1993. Presidência da República Casa Civil, 1993. Disponível em: <http://www.planalto.gov.br/ccivil_03/leis/18666cons.htm>. Acesso em: 01 de agosto de 2020.

${ }^{18}$ BRASIL. Medida Provisória 926 de 20 de março de 2020. Presidência da República Casa Civil, 2020. Disponível em: <http://www.planalto.gov.br/ccivil_03/_ato20192022/2020/Mpv/mpv926.htm>. Acesso em: 01 de agosto de 2020.

${ }^{19}$ BRASIL. Lei 8.666 de 21 de junho de 1993. Presidência da República Casa Civil, 1993. Disponível em: $<$ http://www.planalto.gov.br/ccivil_03/leis/18666cons.htm>. Acesso em: 01 de agosto de 2020.

20 A Lei do Coronavírus determina em seu artigo $4^{\circ}, \S 2$ que os processos de dispensa de licitação deverão ser disponibilizados em base pública até 5 dias após a realização do ato:

“Art. 4 É dispensável a licitação para aquisição ou contratação de bens, serviços, inclusive de engenharia, e insumos destinados ao enfrentamento da emergência de saúde pública de importância internacional de que trata esta Lei.

$\S 2^{\mathrm{o}}$ Todas as aquisições ou contratações realizadas com base nesta Lei serão disponibilizadas, no prazo máximo de 5 (cinco) dias úteis, contado da realização do ato, em site oficial específico na internet, observados, no que couber, os requisitos previstos no $\S 3^{\circ}$ do art. $8^{\circ}$ da Lei $n^{\circ} 12.527$, de 18 de novembro de 2011, com o nome do contratado, o número de sua inscrição na Secretaria da 
disponíveis para acesso público, ou disponibilizados sem fundamentação, o que limita em parte o escopo da pesquisa.

A grande maioria dos casos de dispensa licitatória, em todos os estados, se limitava a apontar uma referência abstrata a uma norma, sem qualquer outra referência aos fatos ou ao nexo entre as circunstâncias e a norma. Por exemplo, no processo $n^{\circ}$ 03210189.000065/2020-13 do Estado do Rio Grande do Norte ${ }^{21}$, que se refere sobre execução dos serviços de manutenção corretiva em respiradores pulmonares e umidificadores para ventilação mecânica, a justificativa da decisão ocorre do seguinte modo:

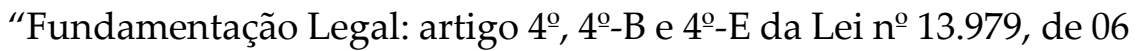
de fevereiro de 2020".

A referência simplificada e em abstrato a uma norma está longe de responder às demandas básicas de justificação do ato de dispensa licitatória. Se estes casos de referência superficial à norma forem acrescentados à base geral de análise, nenhum estado da federação, em regra, justificou minimamente suas decisões.

É possível que, na base pública dos estados, em que os processos são disponibilizados ao acesso público, a justificação específica do ato não tenha sido colacionada pelos gestores? Sim-embora improvável. Para evitar interpretação diversa, decidimos desconsiderar estes processos com mera referência geral a dispositivo normativo-que, como dissemos, são a vasta maioria dos processos de dispensa licitatória - e concentramos a análise nos demais casos em que a dispensa licitatória conta com alguma forma de justificação escrita que vá além da norma legal.

\subsection{Norte}

\subsubsection{Acre}

No Acre, foram identificados diversos processos de dispensa de licitação, porém apenas em sete deles foi localizado Termo de Referência da contratação direta.

\footnotetext{
Receita Federal do Brasil, o prazo contratual, o valor e o respectivo processo de aquisição ou contratação, além das seguintes informações:

I - o ato que autoriza a contratação direta ou o extrato decorrente do contrato;

II - a discriminação do bem adquirido ou do serviço contratado e o local de entrega ou de prestação;

III - o valor global do contrato, as parcelas do objeto, os montantes pagos e o saldo disponível ou bloqueado, caso exista;

IV - as informações sobre eventuais aditivos contratuais;

$\mathrm{V}$ - a quantidade entregue em cada unidade da Federação durante a execução do contrato, nas contratações de bens e serviços.

VI - as atas de registros de preços das quais a contratação se origine."

${ }^{21}$ GOVERNO DO ESTADO DO RIO GRANDE DO NORTE. PORTAL DA TRANSPARÊNCIA, 2020. Disponível em: <http://transparencia.rn.gov.br/docs/comprasservicos/ContratosCOVID19/Contrato-n20.00698CAERN.pdf> Acesso em 25 de agosto de 2020.
} 
Como o portal de transparência do Estado se encontrava em manutenção até a data de formulação do presente documento, não foi possível coletar números específicos de cada processo.

Dentre os processos com Termos de Referência, quatro possuíam ${ }^{22}$, em sua justificativa, os três elementos básicos supracitados: a fundamentação legal, a análise circunstancial e a ponte entre a lei e a realidade.

Em um destes $\operatorname{casos}^{23}$, o documento destaca que a transmissão do vírus foi considerada comunitária no Brasil através da Portaria 424/2020 ${ }^{24}$ e que a contratação teria por base o índice transmissão da doença, por conta de tais fatos, a Lei 13.979/202025 pode ser aplicada em um contexto de dispensa de licitação. Neste Termo, também se argumentou que os fornecedores que já possuíam contratos com a administração pública não tinham os produtos necessários para pronta entrega e os contratos firmados para a aquisição destes, em período anterior à ocorrência da pandemia, não poderiam suprir as necessidades por conta do aumento do número de pessoas que contraíram o vírus.

Nota-se também o caso do Processo 22/202026, que se refere à compra de álcool em gel e máscaras em caráter emergencial. O processo se fundamenta na Lei

22 ACRE. Processo 19-20-005430. Portal de Transparência do Acre, 2020. Disponível em: $<$ http://app.tce.ac.gov.br/portaldaslicitacoes/>. Acesso em: 02 de agosto de 2020; ACRE. Processo 22/2020. Portal de Transparência do Acre, 2020. Disponível em: $<$ http://app.tce.ac.gov.br/portaldaslicitacoes/paginas/publico/portal/processos/listas/dispensa/ger enciador.xhtml>. Acesso em: 02 de agosto de 2020; ACRE. Portal de Transparência do Acre, 2020. Disponível

em: $<$ http://app.tce.ac.gov.br/portaldaslicitacoes/paginas/publico/portal/processos/listas/dispensa/ger enciador.xhtml>. Acesso em: 02 de agosto de 2020; ACRE. Portal de Transparência do Acre, 2020. Disponível

em: $<$ http://app.tce.ac.gov.br/portaldaslicitacoes/paginas/publico/portal/processos/listas/dispensa/ger enciador.xhtml $>$. Acesso em: 02 de agosto de 2020.

23 ACRE. Portal de Transparência do Acre, 2020. Disponível em: $<$ http://app.tce.ac.gov.br/portaldaslicitacoes/paginas/publico/portal/processos/listas/dispensa/ger enciador.xhtml>. Acesso em: 02 de agosto de 2020.

${ }^{24}$ BRASIL. Diário oficial da União, 2020. Disponível em: <https://www.in.gov.br/en/web/dou//portaria-n-424-de-22-de-junho-de-2020-262970445>. Acesso em: 02 de agosto de 2020.

${ }^{25}$ BRASIL. Lei 13.979 de 06 de fevereiro de 2020. Presidência da República Casa Civil, 2020. Disponível em: <http://www.planalto.gov.br/ccivil_03/leis/18666cons.htm>. Acesso em: 01 de agosto de 2020.

26 ACRE. Processo 22/2020. Portal de Transparência do Acre, 2020. Disponível em: $<$ http://app.tce.ac.gov.br/portaldaslicitacoes/paginas/publico/portal/processos/listas/dispensa/ger enciador.xhtml>. Acesso em: 02 de agosto de 2020. 
$13.979 / 2020^{27}$, no artigo 24 e 26 da Lei 8.666/9328, na Portaria 188 de $2020^{29}$ e Decreto 5.496 de $2020^{30}$. Além disso, argumenta também sobre a necessidade de dispensa de licitação por conta de situação emergencial e dos equipamentos solicitados representam uma forma de proteção preventiva contra a disseminação do Covid19 vírus. Foi permitida a adoção de medidas de urgência que possibilitem reduzir o impacto da pandemia, sendo ações imediatas de prevenção imprescindíveis por conta da iminente ameaça do vírus e, portanto, havendo necessidade de contratação direta para compra de itens emergenciais para o combate ao Coronavírus.

Em relação aos outros três processos examinados, dois deles ${ }^{31}$ cumpriram apenas dois dos critérios necessários: fundamentação legal e análise circunstancial. Contudo, não houve correlação entre a lei e a realidade, portanto, o terceiro critério não foi satisfeito.

Um dos processos de dispensa de licitação ${ }^{32}$ somente possui um dos elementos básicos: a referência à lei. Com isso, essas justificativas são caracterizadas como insuficientes.

\subsubsection{Amapá}

No Amapá, foram analisados quatro processos de dispensa de licitação. Dentre esses, apenas o processo 330101.2020.000027-SEJUSP - 00002/SEJUSP/2020a ${ }^{33}$ continha os três elementos básicos: a fundamentação legal, a análise circunstancial e a ponte entre a lei e a realidade. Nestes processos, portanto, estão presentes os

27 BRASIL. Lei 13.979 de 06 de fevereiro de 2020. Presidência da República Casa Civil, 2020. Disponível em: <http://www.planalto.gov.br/ccivil_03/leis/18666cons.htm>. Acesso em: 01 de agosto de 2020.

${ }^{28}$ BRASIL. Lei 8.666 de 21 de junho de 1993. Presidência da República Casa Civil, 1993. Disponível em: <http://www.planalto.gov.br/ccivil_03/leis/18666cons.htm>. Acesso em: 01 de agosto de 2020.

29 BRASIL. PORTARIA 188 DE 2020. Ministério da Saúde, 2020. Disponível em: $<$ https://www.in.gov.br/web/dou/-/portaria-n-188-de-3-de-fevereiro-de-2020-241408388>. Acesso em: 25 de agosto de 2020.

30 BRASIL. DECRETO 5.496 DE 2020. Disponível em: $<$ https://www.legisweb.com.br/legislacao/?id=394471>. Acesso em: 25 de agosto de 2020.

${ }^{31}$ ACRE. Portal de Transparência do Acre. Secretaria de Saúde do Estado, 2020. Disponível em: $<$ http://app.tce.ac.gov.br/portaldaslicitacoes/paginas/publico/portal/processos/listas/dispensa/ger enciador.xhtml>. Acesso em: 02 de agosto de 2020; ACRE. Portal de Transparência do Acre, 2020. Disponível $<$ http://app.tce.ac.gov.br/portaldaslicitacoes/paginas/publico/portal/processos/listas/dispensa/ger enciador.xhtml>. Acesso em: 02 de agosto de 2020.

32 ACRE. Portal de Transparência do Acre, 2020. Disponível em: $<$ http://app.tce.ac.gov.br/portaldaslicitacoes/paginas/publico/portal/processos/listas/dispensa/ger enciador.xhtml>. Acesso em: 02 de agosto de 2020.

${ }^{33}$ AMAPÁ. Processo 330101.2020.000027-SEJUSP e 00002/SEJUSP/2020. Secretaria do Estado de Saúde Pública, 2020. Disponível em: <http://cosiga.ap.gov.br/covid/16489/anexo/TERMO_04__E.P._DA_SILVA_-paginas-1-3_-_assinado.pdf >. Acesso em: 02 de agosto de 2020. 
critérios mínimos para considerar a justificativa da dispensa de licitação como suficiente.

Já nos processos 300101.0005.0082.0330/2020 e 300101.0005.0082.0330-2020 ${ }^{34}$, foram apresentados apenas dois elementos básicos, fundamentação legal e análise circunstancial, não tendo sido formulada, nestes casos, uma correlação entre fatos e as hipóteses normativas. Além desses, no processo 006/2020, identificou-se apenas um dos elementos, a fundamentação legal ${ }^{35}$. Por conseguinte, nota-se que as justificativas desses processos são caracterizadas como insuficientes.

Tomando-se este último como forma de exemplificação, a sua fundamentação teve por base apenas a lei, ou seja, argumentou que o processo de dispensa de licitação estaria fundamentado no artigo 37, XXI da Constituição Federal, na Lei 13.979/20 e o artigo 24, IV da Lei 8.666/93.

\subsubsection{Amazonas}

No Amazonas, os processos de dispensa de licitação encontram-se no portal da SEFAZ - Secretaria do Estado da Fazenda e no portal da Transparência do Estado do Amazonas. Para esta análise, foram selecionadas seis dispensas. Os processos $\mathrm{n}^{\circ}$ 011304.007528/2020 (Escola Superior de Ciências da Saúde) e processo 017306.000830/2020 ${ }^{36}$ apresentaram em suas justificativas os três elementos básicos: fundamentação legal, análise circunstancial e a ponte entre a lei e a realidade, portanto, sendo classificados como suficientes.

Para exemplificar, cabe detalhar a dispensa $\mathrm{n}^{\circ} 011304.007528 / 2020$. O processo teve como fundamentação legal o Art. 24, inciso IV, da Lei n 8.666/1993 e inciso II do $\S 2^{\circ}$ do art. $7^{\circ}$ da lei 8.666/93. A análise circunstancial foi fundamentada na observação do índice de transmissão no Estado, bem como na necessidade de proteção dos profissionais e suas famílias. Por fim, o terceiro elemento, ponte entre a lei e a realidade, foi construído a partir de uma correlação entre os fatos e as previsões normativas. Segue-se a transcrição da justificativa:

34 AMAPÁ. Processo 004/2020. Centro de Reabilitação do Amapá, 2020. Disponível em: $<$ http://cosiga.ap.gov.br/covid/15769/anexo/justificativa_de_dispenca.pdf $>$. Acesso em: $02 \mathrm{de}$ agosto de 2020; AMAPÁ. Processo 300101.0005.0082.0330/2020. Coordenadoria de Gestão de Compras do Amapá. Secretaria de Saúde do Amapá, 2020. Disponível em: <http://cosiga.ap.gov.br/covid/15681/anexo/TERMO_DE_DISPENSA_300101.0005.0082.03302020.pdf>. Acesso em: 02 de agosto de 2020.

${ }^{35}$ AMAPÁ. Processo 006/2020. Superintendência de Vigilância em Saúde. Governo do Estado do Amapá, $2020 . \quad$ Disponível em: <http://cosiga.ap.gov.br/covid/15995/anexo/TERMO_DE_DISPENSA_DE_LICITACAO.pdf>. Acesso em: 02 de agosto de 2020.

36 AMAZONAS. Processo 017306.000830/2020. Portal da Transparência, 2020. Disponível em: $<$ http://www.transparencia.am.gov.br/covid-19/licitacoes/>. Acesso em: 02 de agosto de 2020; AMAZONAS. Processo 011304.007528/2020. Portal da Transparência, 2020. Disponível em: $<$ http://sistemas.sefaz.am.gov.br/sgc-

am/contratos.do? method=detalharContrato\&idContrato=21441>. Acesso em: 02 de agosto de 2020. 
"ESCOLHA DO FORNECEDOR: Temos a informar que a empresa EXPANSÃO INDUSTRIA GRÁFICA DA AMAZONIA LTDA - EPP inscrito sob o CNPJ $n^{\circ}$ 03.023.261/0001-15, fora selecionada para o fornecimento de avental descartável, que corresponde ao montante $R \$$ 171.200,00 (cento e setenta um mil e duzentos reais), conforme mapa comparativo $n^{\circ}$ 021/2020. Cumpre-se evidenciar que: I) Após minuciosa análise das mesmas, o preço que provém da proposta da empresa em apreço demonstrou maior economicidade, nos moldes do Mapa Comparativo juntado aos autos, como exige o inciso II do $\S 2^{\circ}$ do art. $7^{\circ}$ da lei 8.666/93; II) A mesma atende a todos os requisitos solicitados no Projeto Básico elencado aos autos, bem como legislação vigente, em especial a Lei 8.666/93; III) É do ramo pertinente. AMPARO LEGAL: DIREITO ADMINISTRATIVO. DISPENSA DE LICITAÇÃO. CONTRATAÇÃO. DISPENSA. AQUISIÇÃO"

Em contrapartida, nos processos $n^{\circ}$ 017133.000150/2019; 017101.010804/2020; 017101.010945/2020; e 017304.001022/2020 37 foram identificados apenas dois elementos básicos, sendo eles: a fundamentação legal e a observação da realidade, não se tendo desenvolvido, nos casos em questão, uma relação entre estes dois elementos básicos. Por este motivo, as justificativas apresentadas para que ocorresse a dispensa de licitação são classificadas como insuficientes, conforme os critérios analisados.

Cabe destacar que, no processo $\mathrm{n}^{\circ}$ processo 017101.010804/2020, houve autorização de dispensa de licitação para contratação de empresa especializada em serviços de transporte sanitário (UTI aérea), no valor de 4.151 .079 reais, com base na fundamentação de necessidade do bem para atender casos suspeitos e confirmados de Coronavírus e na Lei no 8.883/94, Lei 13.979/20, Portaria 395 de 2020, Medida Provisória 926 de 2020 e Decreto № 42.061 de 16 de março de 2020.

\subsubsection{Pará}

37 AMAZONAS. Processo 017133.000150/2019. Portal da Transparência, 2020. Disponível em: $<$ http://sistemas.sefaz.am.gov.br/sgc-

am/contratos.do?method=detalharContrato\&idContrato=21450>. Acesso em: 02 de agosto de 2020; AMAZONAS. Processo 017101.010804/2020. Portal da Transparência. Unidade de Saúde do Estado do Amazonas, 2020. Disponível em: <http://sistemas.sefaz.am.gov.br/sgcam/contratos.do?method=detalharContrato\&idContrato=21487>. Acesso em: 02 de agosto de 2020; AMAZONAS. Processo 017101.010945/2020. Portal da Transparência, 2020. Disponível em: $<$ http://sistemas.sefaz.am.gov.br/sgc-

am/contratos.do?method=detalharContrato\&idContrato=21409>. Acesso em: 02 de agosto de 2020; AMAZONAS. Processo 017304.001022/2020. Portal da Transparência, 2020. Disponível em: $<$ https://www.e-

compras.am.gov.br/publico/transparencia_licitacoes_detalhes.asp?ident=205533>. Acesso em: 02 de agosto de 2020 . 
No estado do Pará foram observados seis processos de dispensa de licitação, dentre os quais dois possuíam ${ }^{38}$ os três critérios básicos em suas defesas: a fundamentação legal, a análise circunstancial e a ponte entre o mundo real e o mundo normativo.

Dentre os processos suficientes, serão detalhadas suas justificativas.

A dispensa ${ }^{\circ}$ 7/2020-2905001, da Prefeitura Municipal de Augusto Corrêa, teve como fundamentação legal a Lei $\mathrm{n}^{\circ} 13.979 / 2020$ e, por análise circunstancial, a observação do índice de contaminação. O último elemento, ponte entre o direito e a realidade, foi realizado por meio da demonstração de como a realidade se configura como uma das hipóteses para a dispensa de licitação.

Já no processo $n^{\circ}$ 01606001/20, de Ponta de Pedras, a fundamentação legal teve por base o art. $4^{\circ}$ da lei $\mathrm{n}^{\circ} 13.979 / 2020$ e, subsidiariamente, o art. 24, inciso IV da lei $n^{\circ} 8.666 / 1993$. A análise circunstancial foi fundamentada na observação da extrema necessidade de prevenção e controle, assim como do item a ser contratado. Por último, a ponte entre a lei e a realidade foi construída a partir da correlação entre os fatos e as normas. Abaixo, segue-se parte da justificação:

“Fundamentada no art. $4^{\mathrm{o}}$ da lei $13.979 / 20$ e suas alterações, e subsidiariamente no art. 24, inciso iv da lei $n^{-0} 8.666 / 93$. Deve-se notar, também, a obediência às medidas de contenções divulgadas pela Organização Mundial da Saúde, que propicia a aquisição de materiais e/ou contratação de serviços essenciais para o combate a disseminação do vírus em nosso município, que por sua vez, viabiliza a contratação. A aquisição de IVERMECTINA 6MG, destinado a suprir as necessidades básicas no tratamento e recuperação da população infectada pelo novo coronavírus (COVID-19). Devido ao aumento exponencial na demanda decorrente do novo coronavírus (COVID-19). Os cuidados com a prevenção e controle de pacientes são de extrema necessidade, devido ao grande número de infectados os cuidados devem ser redobrados. Considerando que a assistência à saúde é garantia pelo sistema único de saúde (SUS) e para isto toda a linha de cuidado deve ser efetiva e eficaz, desde a atenção básica até os procedimentos de alta complexidade, de forma organizada e hierarquizada, com foco na qualidade dos serviços prestados, segundo o grau de complexidade de assistência requerida."

${ }^{38}$ PARÁ. Processo 7/2020-2905001. Tribunal de contas dos Municípios do Estado do Pará, 2020. Disponível em: $<$ https://www.tcm.pa.gov.br/mural-delicitacoes/licitacoes/ficha/QT6FIMNRVS65UQ>. Acesso em: 02 de agosto de 2020; PARÁ. Processo 01606001/20. Tribunal de contas dos Municípios do Estado do Pará, 2020. Disponível em: $<$ https://www.tcm.pa.gov.br/mural-de-licitacoes/licitacoes/ficha/QT6FIMNpWU55UU>. Acesso em: 02 de agosto de 2020. 
Já nos processos $n^{\circ} 4 / 2020, n^{\circ} 632 / 2020$ e $n^{\circ} 733 / 2020^{39}$, apenas um elemento mínimo, fundamentação legal, foi encontrado, caracterizando essas justificativas como insuficientes.

Além disso, no processo $\mathrm{n}^{\circ} 837 / 2020^{40}$, foram identificados dois elementos básicos: fundamentação legal e análise circunstancial. A fundamentação legal teve por base os dispositivos: Medida Provisória 926/2020, artigo 24, IV, da Lei 8.666/1993, artigo 26 da Lei 9.666/1993, artigo 196 da Constituição, Decreto Legislativo de 06/2020, Decreto de Calamidade Pública do Governo do Estado do Pará 687/2020 e Medida Provisória 961/2020. Na análise circunstancial, argumentou-se sobre o cenário mundial do Coronavírus, bem como a necessidade da aquisição dos itens a serem contratados pelo Município de Afuá. Não foi identificado o elemento de ponte entre a lei e a realidade, portanto, nota-se que as justificativas dispostas nestes processos são caracterizadas como insuficientes.

\subsubsection{Rondônia}

No estado de Rondônia foram identificados seis processos de dispensa de licitação. Dentre eles, quatro ${ }^{41}$ tinham em suas justificativas os três elementos

${ }^{39}$ PARÁ. Processo 4/2020. Tribunal de contas dos Municípios do Estado do Pará, 2020. Disponível em: $\quad<$ https://www.tcm.pa.gov.br/mural-de-licitacoes/licitacoes/ficha/QT6FIMNpWQ51UU>. Acesso em: 02 de agosto de 2020; PARÁ. Processo 632/2020. Tribunal de contas dos Municípios do Estado do Pará. Prefeitura Municipal de Afuá, 2020. Disponível em: $<$ https://www.tcm.pa.gov.br/mural-de-licitacoes/licitacoes/ficha/QT6FlMNpWU14UQ>. Acesso em: 02 de agosto de 2020; PARÁ. Processo 733/2020. Tribunal de contas dos Municípios do Estado do Pará. Prefeitura Municipal de Afuá, 2020. Disponível em: <https://www.tcm.pa.gov.br/muralde-licitacoes/licitacoes/ficha/QT6FIMNpWVx40Z>. Acesso em: 02 de agosto de 2020.

${ }^{40}$ PARÁ. Processo 837/2020. Tribunal de contas dos Municípios do Estado do Pará, 2020. Disponível em: $<$ https://www.tcm.pa.gov.br/mural-delicitacoes/licitacoes/ficha/QT6FIMNp2a310d\#licitacao>. Acesso em: 02 de agosto de 2020.

${ }^{41}$ RONDÔNIA. Processo: 0036.237367/2020-21. Portal da Transparência. Secretaria de Estado da Saúde, $2020 . \quad$ Disponível em: $<$ http://www.transparencia.ro.gov.br/Arquivo/VisualizarArquivo?pEncArquivoId=hl7UzK6DJX0fR3lvTg87_95pcq_tVqSVrTEotZ3HRgWz4t4VwCcbE0qsmMSYr1-

qV3q_sMsPqbafyoNxnuqZj4nRPN_58zJ2hqvePjGsD03QU4L>. Acesso em: 02 de agosto de 2020; RONDÔNIA. Portal da Transparência. Secretaria de Estado da Saúde, 2020. Disponível em: $<\mathrm{http}$ //www.transparencia.ro.gov.br/Arquivo/VisualizarArquivo?pEncArquivoId=7YPL9zi61Zj pXAm9Bv2JLqdzNQFFmRfccEVfG6rXONYsNQF_LUNODd-

4Mj55pplbL1MhTARF7k_13P6zDECpiWUbXk5z-CPS4ttIC5mnzY3QU4L>. Acesso em: 02 de agosto de 2020; RONDÔNIA. Portal da Transparência. Superintendência Estadual de Compras e Licitações, 2020.2 Disponível em: $<$ http://www.transparencia.ro.gov.br/Arquivo/VisualizarArquivo?pEncArquivoId=4_YN_vi_ym 3dPn_ZELVkCYkrXDklCNpFWk3AMQmAtv119hNwGMNrNMorY9Qulbf-

iQxjtKVK00ahxzP8qtuuKHiIq30LkYEHlxxKbnhMubc3QU4L>. Acesso em: 02 de agosto de 2020; RONDÔNIA. Portal da Transparência. Secretaria de Estado da Saúde, 2020. Disponível em: $<\mathrm{http}$ //www.transparencia.ro.gov.br/Arquivo/VisualizarArquivo?pEncArquivoId=jH9afHbH9R 
básicos observados: a fundamentação legal, a análise circunstancial e a ponte entre a norma e a realidade. Todos obedeceram aos critérios mínimos básicos para uma justificativa suficiente da dispensa.

A título exemplificativo, destaca-se a dispensa de licitação requisitada pelo Centro de Medicina Tropical de Rondônia - CEMETRON e Laboratório de Análises Clínicas do Estado de Rondônia - LEPAC/RO. Nesse processo, foram identificados os três requisitos mínimos da justificativa de dispensa. A dispensa teve como fundamentação legal o Decreto Legislativo 06 de 20/03/2020, o artigo 65 da Lei Complementar 101, o Decreto 24.887/2020, o Decreto 24.871/2020 e o artigo 4 da Lei 13.979/2020. Na análise circunstancial, identificada no termo de referência do processo, o gestor argumentou a necessidade de realização do processamento das amostras para o diagnóstico da Covid-19, bem como o retorno da realização do exame TRM-TB (tuberculose) em pacientes com suspeita de Covid-19, que estava suspensa em decorrência da falta do equipamento de proteção objeto da dispensa. Por fim, o elemento de ponte entre a lei e a realidade foi construído a partir da demonstração de emergência da situação que é abarcada pelos dispositivos legais. Para detalhar essa correlação, transcreve-se a justificativa do processo:

“Considerando que a contratação emergencial é o meio adequado, efetivo e eficiente de afastar o risco iminente detectado. A caracterização de situação emergencial, que autoriza o procedimento de dispensa de licitação, deve estar demonstrada no respectivo processo administrativo, evidenciando que a contratação imediata é a via adequada e efetiva para eliminar iminente risco de dano ou de comprometimento da segurança de pessoas, obras, serviços, equipamentos e outros bens, públicos ou particulares. Não se presta a esse fim a presença de pronunciamento técnico apontando a existência de graves problemas estruturais, se a interdição do local, por si só, suspenderia eventual risco à segurança dos frequentadores, e descaracterizaria a situação de urgência, possibilitando a realização do devido procedimento licitatório. A contratação direta com base na emergência prevista no inciso IV do art. 24 da Lei 8.666/1993 deve ser adequadamente justificada, de maneira a se afastar qualquer tipo de dúvida quanto à regularidade no uso do dispositivo. A situação adversa ou emergencial, a ensejar a contratação direta, não pode ter se originado, total ou parcialmente, da falta de planejamento, da desídia administrativa ou da má gestão dos recursos disponíveis, ou seja, não pode, em alguma medida, ser atribuída à culpa ou dolo do agente público que tinha

OQ5a0LD_9U-Q5mAlT9bcJeUqJ05s4kzq0BPsMz2Rvzy_TVohNq0z5XJq70z1Ifw4VtTJULv0R62AEWMgQoEERxrfRM8Q9qCk3QU4L>. Acesso em: 02 de agosto de 2020. 
o dever de agir para prevenir a ocorrência de tal situação. Considerando que o Hosp. CEMETRON é referência para o atendimento aos pacientes acometidos pela Covid-19, classificados como moderados a graves, a necessidade da realização do processamento das amostras para o diagnóstico da Covid-19, amostras estas com alto índice de contaminação, a imposição de requisitos de segurança biológica através da utilização de Equipamentos de Proteção Coletiva - EPCs dentre os quais as cabines de segurança biológicas (CSB) são geralmente usadas como contenção primária no trabalho com agentes de risco biológico, minimizando a exposição do operador, do produto e do ambiente, a suspensão da realização de exame TRM-TB (tuberculose) de pacientes suspeitos de Covid-19, em decorrência da falta do referido equipamento de proteção. Torna-se imprescindível e plenamente justificável a Aquisição deste equipamento."

Além desses, houve outros dois dos processos que possuíam apenas os critérios da fundamentação legal e da observação da realidade. Nestes casos, não foi apresentada qualquer "ponte" entre os dois elementos básicos e, portanto, os argumentos usados na justificativa são caracterizadas como insuficientes.

\subsubsection{Roraima}

No estado de Roraima, foram identificados quatro processos de dispensa de licitação. Dentre eles, o processo no ${ }^{0}$ 082/2020 (Prefeitura de Rorainópolis) ${ }^{42}$ continha dois dos critérios básicos: a fundamentação legal (com base no art. 24, inc. IV, da

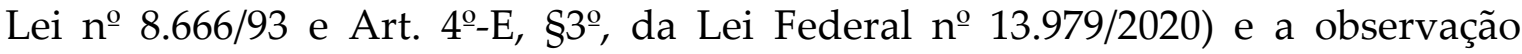
circunstancial (com fundamento na necessidade de prevenção da transmissibilidade do vírus no município). Contudo, não foi elaborada correlação entre os fatos e as hipóteses normativas, prescindindo do terceiro elemento básico, ponte entre a realidade e o direito. Os demais processos ${ }^{43}$ continham somente um dos elementos básicos: fundamentação legal.

42 RORAIMA. Processo no 082/2020. Diário Oficial da União. Prefeitura Municipal de Rorainópolis, 2020. Disponível em: <https://www.in.gov.br/en/web/dou/-/aviso-de-dispensa-de-licitacao260834961>. Acesso em: 02 de agosto de 2020.

RORAIMA. Processo no 013/2020. Diário Oficial da União. Prefeitura Municipal de Amajari, 2020. Disponível em: <https://www.in.gov.br/en/web/dou/-/aviso-de-dispensa-de-licitacao256322117?inheritRedirect=true\&redirect=\%2Fweb\%2Fguest $\% 2 \mathrm{Fsearch} \% 3 \mathrm{FqSearch} \% 3 \mathrm{DDispens}$ a $\% 2520$ de $\% 2520$ licita $\% 25 \mathrm{C} 3 \% 25 \mathrm{~A} 7 \% 25 \mathrm{C} 3 \% 25 \mathrm{~A} 30 \% 2520$ roraima>. Acesso em: 02 de agosto de 2020; RORAIMA. Processo ${ }^{\circ}$ 117/2020. Diário Oficial da União. Prefeitura Municipal de São João da Baliza, 2020. Disponível em: <https://www.in.gov.br/en/web/dou/-/extrato-de-dispensa-delicitacao-

258736342?inheritRedirect=true\&redirect=\%2Fweb\%2Fguest $\% 2$ Fsearch $\% 3 F q S e a r c h \% 3 D D i s p e n s$ a\%2520de $\% 2520$ licita $\% 25 \mathrm{C} 3 \% 25 \mathrm{~A} 7 \% 25 \mathrm{C} 3 \% 25 \mathrm{~A} 30 \% 2520$ roraima>. Acesso em: 02 de agosto de 
Por esse motivo, essas justificativas de dispensa foram caracterizadas como insuficientes.

\subsubsection{Tocantins}

Em Tocantins, foram identificados apenas dois processos de dispensa de licitação. Em ambos (processos $n^{\circ}$ 00005/2020 e 00077/2020) ${ }^{44}$, as justificativas apresentavam apenas um dos elementos básicos, isto é, a fundamentação legal. Consequentemente, essas motivações foram classificadas como insuficientes. Veja o exemplo do processo $n^{\circ} 00077 / 2020$ :

Arts. 60 e 62 da lei 8666/93" (Processo n 00077/2020).

\subsection{Nordeste}

\subsubsection{Alagoas}

No estado de Alagoas, foram analisados pedidos de dispensa de licitação referentes aos órgãos: Universidade Federal de Alagoas - Hospital Universitário Prof. Alberto Antunes, Agência de Defesa e Inspeção Agropecuária de Alagoas, Corpo de Bombeiro Militar do Alagoas e Universidade Federal de Alagoas (UFAL). Nos processos relacionados ao Hospital Universitário Prof. Alberto Antunes ${ }^{45}$ e a UFAL 46 , foram identificadas apenas justificativas legais fundamentadas respectivamente no $\S 2^{-a}$, art. $4^{\circ}$, da Lei $N^{\circ} 13.979 / 2020$ e Ministério da Educação, Ofício Circular $\mathrm{N}^{\circ}$ 04/2020/CGPO/DIFES/SESU/SESU-MEC. Logo, por conter apenas um elemento, essas justificativas se classificam como insuficientes.

2020; Diário Oficial do Municípios de Roraima, 20 de Maio de 2020. Processo n 152/2020 - SMSA. Dispensa de Licitação ${ }^{\circ}$ 025/2020 - CPL.

${ }^{44}$ TOCANTINS. Licitação 00005/2020. Portal da Transparência. Ministério da Educação, 2020. Disponível

em: $<$ http://www.portaltransparencia.gov.br/contratos/96207404?ordenarPor=descricao\&direcao=asc \#termoBuscaPortal>. Acesso em: 02 de agosto de 2020; TOCANTINS. Licitação 00077/2020. Portal da Transparência. Ministério da Defesa, 2020. Disponível em: <http://www.portaltransparencia.gov.br/contratos/103707329?ordenarPor=descricao\&direcao=as c $>$. Acesso em: 02 de agosto de 2020.

45 REPÚBLICA FEDERATIVA DO BRASIL. Processo 23540.005668/2020-93. Hospitais Universitários Federais, Ministério da Educação, 2020. Disponível em: $<$ http://www2.ebserh.gov.br/documents/221436/5033452/26.03+Dispensas+de+Licita\%C3\%A7\%C 3\%A3o+para+o+Combate+ao+COVID-19+-+ATUALIZADA+EM+26-05-2020.pdf/afa7fa38-0f7b4dee-9be9-c10e7050651a> Acesso em 21 de julho de 2020.

${ }^{46}$ REPÚBLICA FEDERATIVA DO BRASIL. DL 04.2020. Universidade Federal do Alagoas, 2020. Disponível em: <https://ufal.br/transparencia/licitacoes/dispensa-de-licitacao/2020/justificativadl-04-2020.pdf/view> Acesso em 21 de julho de 2020. 
No processo de dispensa relacionado a Agência de Defesa e Inspeção Agropecuária de Alagoas ${ }^{47}$, foram identificadas as justificativas legal (fundamentada no Decreto $\mathrm{N}^{\circ}$ 69.541, de 19 de março de 2020) e social (com base na necessidade de aquisição dos itens para dar prosseguimento no combate ao Coronavírus) e, devido à ausência de construção da ponte entre a hipótese jurídica e a realidade, a justificativa se classifica como insuficiente. Já no PROCESSO E:01203.0000001068/2020 48, do Corpo de Bombeiros Militar do Estado de Alagoas, identificou-se apenas uma justificativa social, fundamentada na atribuição de prestação de serviço pré-hospitalar do Corpo de Bombeiros no estado e no nível de criticidade dos estoques do item em questão, sem qualquer conexão, contudo, à base normativa, tornando a justificativa insuficiente.

\subsubsection{Bahia}

Na Bahia, os processos relacionados a dispensa de licitação foram localizados no portal da Secretaria da Saúde do Estado da Bahia. Dentre o conjunto analisado, quatro processos ${ }^{49}$ apresentaram apenas o elemento de fundamentação legal, com base no art. $4^{\circ}$ da Lei Federal n 13.979 de 2020 e na Medida Provisória n 926/2020, classificando-se como insuficientes. Destacamos que o referido portal virtual menciona as referidas previsões legais de forma a compreender que todos os processos disponíveis no site possuem essas normativas como argumento.

Ademais, apenas dois processos $\left(\mathrm{n}^{\circ}\right.$ 019.7441.2020.0029889-74 e $\mathrm{n}^{\circ}$ 019.5050.2020.0028421-02 $)^{50}$ apresentaram dois elementos básicos: fundamentação

${ }^{47}$ ALAGOAS. Processo E:52555.0000000785/2020. Portal Da Transparência Graciliano Ramos, 2020. Disponível em: <http://transparencia.al.gov.br/licitacao/contracoes-diretas/>. Acesso em 22 de julho de 2020.

48 GOVERNO DO ESTADO DE ALAGOAS. Processo e:01203.0000001068/2020.Portal da transparência graciliano ramos, 2020. Disponível em: $<$ http://transparencia.al.gov.br/licitacao/contracoes-diretas/> Acesso em 22 de julho de 2020.

${ }^{49}$ GOVERNO DO ESTADO DA BAHIA. Processo 019.8634.2020.0035259-52. SECRETARIA DA SAÚDE, 2020. Disponível em: <http://www.saude.ba.gov.br/wpcontent/uploads/2020/07/Contrato-N\%C2\%BA-048.20-DE-008.20.pdf> Acesso em 22 de julho de 2020; GOVERNO DO ESTADO DA BAHIA. Processo 019.8820.2020.006333-32. SECRETARIA DA SAÚDE, 2020. Disponível em:

< http://www.saude.ba.gov.br/wp-content/uploads/2020/07/AFM-19.123.00562_2020.pdf> Acesso em 22 de julho de 2020; GOVERNO DO ESTADO DA BAHIA. Processo 019.9197.2020.0067967-76. SECRETARIA DA SAÚDE, 2020. Disponível em:

< http://www.saude.ba.gov.br/wp-content/uploads/2020/07/AFM-704.2020.pdf> Acesso em 22 de julho de 2020; GOVERNO DO ESTADO DA BAHIA. Processo 019.7441.2020.0029397-61. SECRETARIA DA SAÚDE, 2020. Disponível em:

$<$ http://www.saude.ba.gov.br/wp-content/uploads/2020/03/19.004.00330_2020.pdf > Acesso em 22 de julho de 2020.

50 GOVERNO DO ESTADO DA BAHIA. Processo 019.7441.2020.0029889-74. SECRETARIA DA SAÚDE, 2020. Disponível em: <http://www.saude.ba.gov.br/wpcontent/uploads/2020/03/DRAGER162020.pdf > Acesso em 22 de julho de 2020.GOVERNO DO ESTADO DA BAHIA. Processo 019.5050.2020.0028421-02. SECRETARIA DA SAÚDE, 2020. 
legal e análise circunstancial. Em ambos, a fundamentação legal teve por base o art. $4^{\circ}$ da Lei Federal n 13.979 de 2020 e a Medida Provisória n ${ }^{\circ}$ 926/2020, enquanto a análise circunstancial foi fundamentada na necessidade de combate a pandemia da Covid-19, classificando-se, portanto, como insuficientes.

\subsubsection{Ceará}

No Estado do Ceará, os processos de dispensa de licitação foram obtidos do Portal de Licitações do Tribunal de Contas do Estado do Ceará. É importante salientar que esses processos são de ordem municipal e serão elencados com seus respectivos municípios, com base nos documentos disponibilizados.

No Município de Guaiuba ${ }^{51}$, o processo analisado apresentou dois elementos básicos: fundamentação legal (com base no Decreto Municipal Nº19/2020 de 23 de março de 2020 e art. $4^{\circ}$, caput, da Lei Federal n ${ }^{\circ} 13.979$ de 6 de fevereiro de 2020) e análise circunstancial (com base na necessidade de aquisição para combate à Covid19). Além disso, o processo também apresentou uma ponte entre a lei e a realidade, demonstrando de que maneira o momento vigente atende as condições jurídicas para que haja a dispensa de licitação, sendo, portanto, classificada como justificativa suficiente.

Em relação ao município de Fortaleza, foram analisados dois processos de dispensa de licitação. No processo P11.9834/202052, do Fundo Municipal de Saúde, foram apresentados dois elementos: fundamentação legal (Lei Federal no 13.979/2020, alterada pela Medida Provisória oㅡ 926 de 20 de março de 2010, art. 2º VI, do Decreto Municipal no 14.611, de 17 de março de 2020 e art. 2º do Decreto Municipal no 14.620, de 20 de março de 2020) e análise circunstancial (com base na necessidade de combate à pandemia e de preços para a aquisição). Já no processo P118794/202053, do Fundo Municipal de Saúde, também foram encontrados dois elementos: fundamentação legal (com base na Lei Federal no 13.979/2020, Decreto Municipal no 14.611, de 17 de março de 2020, Decreto Municipal nº 14.620, de 20 de março de 2020 e Lei Federal no 8.666, de 21 de junho de 1993) e análise circunstancial

Disponível em: <http://www.saude.ba.gov.br/wp-content/uploads/2020/06/Dispensa-003-2020-

Cardioservice-AFM-19.004.00345-2020.pdf> Acesso em 22 de julho de 2020.

${ }^{51}$ GOVERNO DO ESTADO DO CEARÁ. TRIBUNAL DE CONTAS DO ESTADO DO CEARÁ, 2020.

Disponível

$<$ https://licitacoes.tce.ce.gov.br/index.php/dispensa_inexibilidade/detalhes/proc/157535/licit/2482

$0>$ Acesso em 21 de julho de 2020.

${ }^{52}$ GOVERNO DO ESTADO DO CEARÁ. Processo 119834/2020. TRIBUNAL DE CONTAS DO

ESTADO DO CEARÁ, 2020. Disponível em: $<$ https://licitacoes.tce.ce.gov.br/index.php/dispensa_inexibilidade/detalhes/proc/157854/licit/2491 7> Acesso em 22 de julho de 2020.

${ }^{53}$ GOVERNO DO ESTADO DO CEARÁ. Processo 118794/2020. TRIBUNAL DE CONTAS DO ESTADO DO CEARÁ, 2020. Disponível em: $<$ https://licitacoes.tce.ce.gov.br/index.php/dispensa_inexibilidade/detalhes/proc/157947/licit/2495 5> Acesso em 22 de julho de 2020. 
(com base na economicidade dos preços da contratação). Logo, pela ausência de demonstração de argumentos concretos capazes de correlacionar as hipóteses jurídicas com a realidade, as justificativas de ambos os processos se classificam como insuficientes.

No município de São Benedito, o processo de dispensa de licitação analisado (006.30.03.2020 ${ }^{54}$ ), do Fundo Municipal de Saúde, apresentou apenas um elemento básico, justificativa legal, com base na MP 926 e 927 e Decreto 10.212, DECRETO ESTADUAL no 33.510, de 16 de março de 2020 e Decretos Municipal. Conforme os critérios estabelecidos, a justificativa se classifica como insuficiente.

No município de Madalena, analisou-se o processo de dispensa de licitação 3103.01/2020/202055, do Fundo Municipal de Saúde, que apresentou dois elementos básicos: fundamentação legal (fundamentada na Lei № 13.979, de 6 de fevereiro de 2020 - Art. 04 e Medida Provisória no 926, de 20 de março de 2020 - Art. 04) e social (com base na economicidade dos preços), classificando a justificativa como insuficiente devido à não correlação entre as previsões jurídicas e a realidade.

\subsubsection{Maranhão}

No Estado do Maranhão, duas contratações realizadas por meio de dispensa de licitação foram localizadas no portal da Secretaria de Estado das Cidades. Dentre esses processos, foram identificados dois relacionados à Covid-19 ${ }^{56}$. Nos documentos disponibilizados para consulta dessas contratações foram encontradas apenas fundamentações legais, com base no Inciso VI, Art. 24, da Lei $N^{\circ}$ 8.666/1993, Lei $N^{\circ} 13.979 / 2020$ e na Medida Provisória $N^{\circ}$ 926, de 20 de março de 2020, que se classificaram como insuficientes.

Além do portal da Secretaria de Estado das Cidades, os processos de dispensa de licitação do Maranhão também podem ser consultados no portal do Tribunal de Contas do Maranhão. Neste portal, foram extraídos dois processos de licitação. No

${ }^{54}$ GOVERNO DO ESTADO DO CEARÁ. Processo 006.30.03.2020. TRIBUNAL DE CONTAS DO ESTADO DO CEARÁ, 2020.2 Disponível em: $<$ https://licitacoes.tce.ce.gov.br/index.php/dispensa_inexibilidade/detalhes/proc/158133/licit/2503 2> Acesso em 22 de julho de 2020.

${ }^{55}$ GOVERNO DO ESTADO DO CEARÁ. Processo 3103.01/2020/2020. TRIBUNAL DE CONTAS DO ESTADO DO CEARÁ, $2020 . \quad$ Disponível em:<https://licitacoes.tce.ce.gov.br/index.php/dispensa_inexibilidade/detalhes/proc/157271/licit/2 $4720>$ Acesso em 22 de julho de 2020.

${ }^{56}$ GOVERNO DO ESTADO DO MARANHÃO. Processo 68383/2020. SECID, 2020. Disponível em: < https://secid.ma.gov.br/files/2020/06/Ratifica\%C3\%A7\%C3\%A3o-Dispensa-n\%C2\%BA006.2020.pdf $>$. Acesso em 22 de julho de 2020. GOVERNO DO ESTADO DO MARANHÃO. Processo 61883/2020. 2020.2 Disponível em: $<$ https://secid.ma.gov.br/files/2020/04/Ratifica\%C3\%A7\%C3\%A3o-de-Dispensa-n\%C2\%BA-

003.2020.pdf $>$ Acesso em 22 de julho de 2020. 
processo de Dispensa n ${ }^{\circ} 008 / 2020$ Covid-19, da prefeitura Municipal de Carolina ${ }^{57}$, foram identificados dois elementos básicos: fundamentação legal (com base na Lei Federal n 8.666, de 21 de junho de 1993, bem como suas alterações posteriores e na Lei Federal $n^{\circ} 13.979$, de 06 de fevereiro de 2020 e decretos estaduais) e análise circunstancial (fundamentado na necessidade de atendimento da demanda do Hospital Municipal de Carolina com vistas a combater a Covid-19). Devido a falta do elemento de ponte entre o direito e a realidade, a justificativa foi considerada insuficiente.

No Município de Gonçalves Dias, foi analisado o processo de dispensa de licitação $\mathrm{n}^{\circ} 022 / 2020^{58}$. Nesse processo, foram identificados os três elementos básicos: fundamentação legal (com base no Art. 24, Inciso IV da Lei n 8.666/93, combinado com a Lei. $\mathrm{n}^{\circ} 926$ de 2020); análise circunstancial (com base na necessidade de aquisição dos itens em questão, bem como de sua importância no contexto de prevenção ao vírus) e ponte entre a realidade e o direito. Cabe destacar que no termo de referência dessa licença, foram elaboradas perguntas que também foram respondidas. Abaixo, seguem as perguntas retiradas do documento:

“ a) A Lei 13.979/ 20 está em vigor?

b) Porque o insumo ou serviço que se pretende contratar é no contexto da contenção da crise?

c) Que riscos a falta do insumo ou serviço que se pretende contratar trará \segurança de pessoas, obras, prestação de serviços, equipamentos e outros bens, públicos ou particulares, no contexto da contenção da crise?

d) A contratação, considerando o quantitativo e o prazo do contrato, conforme o caso, está limitada à parcela necessária ao atendimento da situação de emergência?"

Em razão de sua extensão, a íntegra da justificativa com as respostas aos seguintes questionamentos não será transcrita (o inteiro teor pode ser consultado no parecer da dispensa ${ }^{\circ}$ 022/2020, disponível no portal do Tribunal de Contas do Estado do Maranhão). No referido processo, em razão da identificação dos três elementos básicos para a dispensa de licitação, a justificativa foi classificada como suficiente.

\subsubsection{Paraíba}

\footnotetext{
${ }^{57}$ GOVERNO DO ESTADO DO MARANHÃO. TRIBUNAL DE CONTAS DO ESTADO DO MARANHÃO, 2020. Processo de Dispensa $\mathrm{N}^{\circ}$ 008/2020. Disponível em: $<$ https://www6.tce.ma.gov.br/sacop/muralsite/muralcovid.zul> Acesso em 25 de agosto de 2020.

58 GOVERNO DO ESTADO DO MARANHÃO. TRIBUNAL DE CONTAS DO ESTADO DO MARANHÃO, 2020. Processo de Dispensa $\mathrm{N}^{\circ}$ 022/2020. Disponível em: $<$ https://www6.tce.ma.gov.br/sacop/muralsite/muralcovid.zul> Acesso em 25 de agosto de 2020.
} 
No Estado da Paraíba, os processos sobre licitações e Covid-19 estão disponíveis no Portal da Transparência do Estado da Paraíba. Foram analisados os processos licitatórios $\mathrm{n}^{\mathrm{o}}$ 23.901.000039.2020 ${ }^{59}$ e 27.000.001668.2020 ${ }^{60}$. As informações disponíveis não apresentam justificativa. Logo, foram classificadas como insuficientes.

\subsubsection{Pernambuco}

No Estado de Pernambuco, os processos de dispensa de licitação foram localizados no Portal da Transparência do Estado. Dentre o conjunto analisado, foram identificados três processos ${ }^{61}$ que apresentaram apenas a análise circunstancial (necessidade de aquisição dos itens para implementar medidas de combate à Covid-19). Outrossim, a análise também verificou os processos n 13575 $5^{62}$ e $n^{\circ}$ 513713-6 que apresentaram, respectivamente, apenas fundamentação legal (sob o art. $4^{\circ}$ da Lei Federal n 13.979/2020) e análise circunstancial (com base nas especificidades do item em questão e a necessidade de sua contratação para realização de testes moleculares). Assim, as justificativas foram classificadas como insuficientes.

\subsubsection{Piauí}

59 GOVERNO DO ESTADO DA PARAÍBA. Processo 23.901.000039.2020. PORTAL DA TRANSPARÊNCIA, 2020. Disponível em: <https://transparencia.pb.gov.br/coronavirus/?rpt=licitacoes_covid> Acesso em: 22 de julho de 2020.

60 GOVERNO DO ESTADO DA PARAÍBA. Processo 27.000.001668.2020. PORTAL DA TRANSPARÊNCIA, 2020. Disponível em: <https://transparencia.pb.gov.br/coronavirus/?rpt=licitacoes_covid> Acesso em: 22 de julho de 2020.

61 GOVERNO DO ESTADO DE PERNAMBUCO. Processo 512928-1. PORTAL DA TRANSPARÊNCIA, $2020 . \quad$ Disponível em: <http://web.transparencia.pe.gov.br/despesas/despesas-detalhadas-covid-19/>. Acesso em 22 de julho de 2020; GOVERNO DO ESTADO DE PERNAMBUCO. Processo 513336-0. PORTAL DA TRANSPARÊNCIA, 2020. Disponível em: <http://web.transparencia.pe.gov.br/despesas/despesas-detalhadas-covid-19/> Acesso em 22 de julho de 2020; GOVERNO DO ESTADO DE PERNAMBUCO. Processo 383019-5. PORTAL DA TRANSPARÊNCIA, $2020 . \quad$ Disponível em: <http://web.transparencia.pe.gov.br/despesas/despesas-detalhadas-covid-19/> Acesso em 22 de julho de 2020.

62 GOVERNO DO ESTADO DE PERNAMBUCO. Processo 13575-5. PORTAL DA TRANSPARÊNCIA, 2020. Disponível em: <http://web.transparencia.pe.gov.br/despesas/despesas-detalhadas-covid-19/> Acesso em 22 de julho de 2020; GOVERNO DO ESTADO DE PERNAMBUCO. Processo 513713-6. PORTAL DA TRANSPARÊNCIA, 2020. Disponível em: < http://web.transparencia.pe.gov.br/despesas/despesas-detalhadas-covid-19/> Acesso em 22 de julho de 2020. 
No Estado do Piauí, as informações referentes à compras, contratações e aquisições encontram-se no Mural de Licitações do Tribunal de Contas do Estado. Os processos disponíveis estão relacionados aos municípios do estado e, para esta pesquisa, foram analisadas dispensas de licitação dos municípios de Tamboril do Piauí, Piracuruca, Esperantina e Floriano.

No processo do Município de Tamboril do Piauí, de identificação LW003412/20 23 no portal do Tribunal de Contas, foram identificados dois elementos: fundamentação legal (baseada no artigo 26 da Lei $n^{\circ}$ 8.6661/93) e análise circunstancial (necessidade de combate à Covid-19). Nos documentos disponibilizados, não se identificou uma correlação entre as previsões normativas e o caso concreto. Por essa razão, a justificativa foi classificada como insuficiente.

No processo de dispensa do Município de Piracuruca ${ }^{64}$, identificado LW003406/20 pelo portal do Tribunal de Contas, foram identificados dois elementos básicos: fundamentação legal (com base nos Art. 24, IV da Lei no 8.666/93 c/c e Art. $4 \S 1^{\circ}$ e $2^{\circ}$ da Lei $n^{\circ}$ 13.979/2020) e análise circunstancial (fundamentada na necessidade de escolha do menor preço). Tendo em vista que a justificativa prescinde do elemento de ponte entre a lei e a realidade, classifica-se como insuficiente.

Já no Município de Esperantina, analisou-se o processo de dispensa de licitação LW-003613/20 ${ }^{65}$ (identificação do Tribunal de Contas) que apresentou os três requisitos básicos: fundamentação legal (Decreto $\mathrm{n}^{\mathrm{0}}$ 18.901, de 19 de março de 2020, do Decreto n⿳0 18.902, de 23 de março de 2020, do Decreto no 18.913 , de 30 de março de 2020, e do Decreto no 18.947, de 22 de abril de 2020 Governo Estado do Piauí e Decretos n ${ }^{\mathrm{o}}$ 191/2020 do município de Esperantina e a Lei Federal no 13.979 , de fevereiro de 2020); análise circunstancial (tendo por argumentação o crescimento significativo de casos na cidade, a necessidade de constatar o real número de infectados e a menor proposta de preços); e ponte entre a lei e a realidade. Nesse último elemento, cabe detalhar sua forma: o gestor argumentou que em vista do número de casos confirmados e de crescimento no município, havia urgência na aquisição dos testes para verificação do número verdadeiro de contaminados. De tal forma, a situação de emergência contemplava a possibilidade de aquisição mais

${ }^{63}$ GOVERNO DO ESTADO DO PIAUÍ. Controle TCE: LW-003412/20. Tribunal de Contas do Estado do Piauí, $2020 . \quad$ Disponível em: $<$ https://sistemas.tce.pi.gov.br/muralic/detalhelicitacao.xhtml?id=352791> Acesso em: 17 de agosto de 2020.

${ }^{64}$ GOVERNO DO ESTADO DO PIAUÍ. Controle TCE: LW-003406/20. Tribunal de Contas do Estado do Piauí, $2020 . \quad$ Disponível em: $<$ https://sistemas.tce.pi.gov.br/muralic/detalhelicitacao.xhtml?id=352785> Acesso em: 17 de agosto de 2020.

${ }^{65}$ GOVERNO DO ESTADO DO PIAUÍ. Controle TCE: LW-003613/20. Tribunal de Contas do Estado do Piauí, $2020 . \quad$ Disponível em: $<$ https://sistemas.tce.pi.gov.br/muralic/detalhelicitacao.xhtml?id=353055> Acesso em: 17 de agosto de 2020. 
rápida, prevista no do inciso II do art. 26 da Lei Federal 8.666 de 21 de junho de 1993. A título exemplificativo, transcreve-se a justificativa contida no termo de referência:

"A aquisição acima se faz necessária para testagem e monitoramento de pessoas com suspeitas/sintomas de contaminação e infectadas pelo novo coronavírus no município. Conforme Decreto $n^{-} 18.901$, de 19 de março de 2020, do Decreto $n^{-}$18.902, de 23 de março de 2020, do Decreto $n^{-} 18.913$, de 30 de março de 2020, e do Decreto $n^{-}$18.947, de 22 de abril de 2020 Governo Estado do Piauí e Decretos $n^{-}$191/2020 do município de Esperantina, que dispõem sobre as medidas de prevenção, combate e enfrentamento do COVID-19, no âmbito do município de Esperantina, em observância a Lei Federal no 13.979, de fevereiro de 2020. Diante disso faz-se necessária a aquisição de teste rápido de forma mais célere enquanto é concluído o processo licitatório para aquisição de outros testes e demais materiais necessários para enfrentamento do novo coronavírus. A cidade de Esperantina vem apresentando um crescimento significativo e em um ritmo acelerado, se comparado aos demais município do estado Piauí. Isso requer que sejam tomadas medidas urgentes e eficazes para a identificação da quantidade real de casos no município, assim como orientar políticas de enfrentamento dessa grave crise, o qual só é possível com conhecimento do número real de caso existente no município. De acordo com dados do Boletim diário da SESAPI, no dia 11 de maio de 2020, Esperantina possui 35 casos confirmados do novo coronavírus. Considerando o que o município já está realizando um procedimento licitatório para compras de teste rápido, materiais e Equipamento de Proteção Individual - EPI; Verificando, que contemplava a possibilidade de aquisição mais rápida, nos termos, então, do inciso II do art. 26 da Lei Federal 8.666 de 21 de junho de 1993; Considerando, então, a declaração do Estado de Calamidade Pública pelo governador, também o grave risco de contágio $e$ morte de pessoas, a Administração municipal, pautada pelas deliberações do Comitê Extraordinário COVID-19; Desta forma, a aquisição será realizada em questão, sendo considera a pesquisa de preço e juntada 03 (três) orçamentos, sendo desconsiderados os preços de contratações similares ou bancos ou sítios oficiais, uma vez tratar-se situação emergencial, nos termos da Medida Provisória $n^{-}$ 926 de 20 de março de 2020. Fato é que, neste momento, há a necessidade de contratação de produtos, cada vez mais escassos em todo território brasileiro e no resto do mundo e cuja falta traz riscos 
concretos à saúde de pessoas que precisam ser atendidos com um diagnóstico preciso".

Portanto, em razão da identificação dos três elementos básicos, a justificativa se caracteriza como suficiente.

Por fim, na análise da dispensa LW-003316/20 ${ }^{66}$ (identificação do portal do Tribunal de Contas) do Município de Floriano, foram identificados dois elementos básicos: fundamentação legal (Art. 24, IV da Lei no 8.666/93 c/c Art. 4 § $1^{\circ}$ e $2^{\circ}$ da Lei n⿳0 13.979/2020) e análise circunstancial (fundamentada na escolha da proposta mais vantajosa). Em razão da justificativa prescindir do elemento de ponte entre a realidade e o direito, foi classificada como insuficiente.

\subsubsection{Rio Grande do Norte}

No Estado do Rio Grande do Norte, foram analisados dois processos de dispensa de licitação. $O$ pedido de dispensa de licitação referente ao pedido administrativo № 403025/202067, Município de Caraúbas, foi publicado no Diário Oficial da União. O documento disponível apresentou apenas fundamentação legal com base no $\S 1^{\circ}$, art. $4^{\circ}$ da Lei Federal $n^{\circ} 13.979$ de 06 de fevereiro de 2020 alterada pela Medida Provisória n 926 de 20 de março de 2020, classificando a justificativa como insuficiente.

Também foi analisado o processo $n^{\circ} 03210189.000065 / 2020-13^{68}$, extraído do Portal da Transparência do Rio Grande do Norte. Nos documentos disponíveis para consulta, até o final desta análise, identificou-se apenas um elemento básico, fundamentação legal, com base no Artigo $4^{\circ}$, 4º-B e $4^{\circ}$-E da Lei nº 13.979, de 06 de fevereiro de 2020. Logo, por prescindir dos elementos básicos de análise circunstancial e ponte entre a realidade e o direito, essa justificativa foi classificada como insuficiente.

\subsubsection{Sergipe}

No Estado de Sergipe, foram analisados quatro pedidos de dispensa de licitação da Secretaria de Estado da Saúde. Nesse conjunto, todos os processos apresentaram apenas dois elementos: fundamentação legal e análise circunstancial. No processo

\footnotetext{
${ }^{66}$ GOVERNO DO ESTADO DO PIAUÍ. Controle TCE: LW-003316/20. Tribunal de Contas do Estado do Piauí, $2020 . \quad$ Disponível em: $<$ https://sistemas.tce.pi.gov.br/muralic/detalhelicitacao.xhtml?id=352685> Acesso em: 17 de agosto de 2020.

67 REPÚBLICA FEDERATIVA DO BRASIL. IMPRENSA NACIONAL, 2020. Disponível em: $<$ https://www.in.gov.br/web/dou/-/aviso-de-dispensa-de-licitacao-n-7/2020-251930859> Acesso em 22 de julho de 2020.

${ }^{68}$ GOVERNO DO ESTADO DO RIO GRANDE DO NORTE. PORTAL DA TRANSPARÊNCIA, 2020. Disponível em: <http://transparencia.rn.gov.br/docs/comprasservicos/ContratosCOVID19/Contrato-n20.00698CAERN.pdf> Acesso em 25 de agosto de 2020.
} 
$\mathrm{n}^{\circ} 020.000 .05173 / 2020-8^{69}$, a fundamentação legal teve por base o art. 24, inciso IV da Lei 8.666/93, enquanto a análise circunstancial fundamentou-se na não disponibilidade dos itens em estoque e necessidade de abastecimento das unidades hospitalares no estado. Nos demais processos ${ }^{70}$, além da fundamentação legal, as análises circunstanciais tiveram por base a necessidade dos itens em questão para auxiliar no combate a pandemia da Covid-19. Assim, a ausência do elemento de construção de uma ponte entre o direito e a realidade para demonstrar de forma concreta a necessidade das dispensas classificou todas as justificativas analisadas como insuficientes.

\subsection{Centro-Oeste}

\subsubsection{Distrito Federal}

No Distrito Federal, o mapeamento das dispensas encontra-se no portal da Secretaria de Saúde do Distrito Federal. Entretanto, dentre os ofícios disponibilizados não foram localizados os documentos que informam o teor da dispensa de licitação, mas apenas o aviso da dispensa para a aquisição do item em específico. Ademais, os processos disponíveis até o momento da análise não faziam menção à Covid-19. Por essa razão, foram analisados outros portais do governo e, no portal da Secretaria de Estado de Educação, foram identificadas duas dispensas de licitação relacionadas à Covid-19.

A dispensa de licitação $n^{\circ} 04 / 2020^{71}$ apresenta três elementos: a fundamentação legal, análise circunstancial e ponte entre lei e realidade. No extenso rol de disposições legais, utilizou-se as leis $n^{\circ}$ 8. 666, de 21 de junho de 1993 e n 13.979 de, 06 de fevereiro de 2020, dentre outras leis e decretos. Na análise circunstancial, foi observado o crescimento no número de casos de Covid-19 no Distrito Federal, bem como a necessidade de adoção de medidas de prevenção. Ademais, o processo também conta com uma ponte entre a lei e a realidade, de forma que após demonstrar a situação de emergência, a gestora aponta as previsões legislativas para essas circunstâncias e evidencia a existência de hipótese para que a aquisição

\footnotetext{
${ }^{69}$ GOVERNO DO ESTADO DE SERGIPE. Processo 020.000.05173/2020-8. TODOS CONTRA O CORONA, 2020. Disponível em: <https://todoscontraocorona.net.br/wpcontent/uploads/2020/07/DL-224.2020.pdf> Acesso em 22 de julho de 2020.

70 GOVERNO DO ESTADO DE SERGIPE. Processo 020.000.06333/2020-0. TODOS CONTRA O CORONA, 2020. Disponível em: <https://todoscontraocorona.net.br/wpcontent/uploads/2020/07/DL-240.2020.pdf>. Acesso em 22 de julho de 2020; GOVERNO DO ESTADO DE SERGIPE. Processo 020.000.06335/2020-1. TODOS CONTRA O CORONA, 2020. Disponível em: <https://todoscontraocorona.net.br/wp-content/uploads/2020/07/DL278.2020.pdf $>$. Acesso em 22 de julho de 2020; GOVERNO DO ESTADO DE SERGIPE. Processo 04.292.445/0001-43. TODOS CONTRA O CORONA, 2020. Disponível em: $<$ https://todoscontraocorona.net.br/wp-content/uploads/2020/07/DL-278.2020.pdf>. Acesso em 22 de julho de 2020.

${ }^{71}$ GOVERNO DO DISTRITO FEDERAL. Processo 04/2020. Secretaria de Saúde do Distrito Federal, $2020 . \quad$ Disponível em: <http://www.educacao.df.gov.br/wpconteudo/uploads/2017/11/Termo_de_Referencia_38389085.pdf> Acesso em 17 de agosto de 2020.
} 
seja realizada na modalidade de dispensa de licitação. Por essa razão, essa dispensa foi classificada como suficiente.

O processo de dispensa $n^{\circ} 05 / 2020^{72}$ que também consta no portal da Secretaria e está relacionado à Covid-19 não pôde ser analisado, pois, até o encerramento da pesquisa, os documentos disponíveis não confirmaram sua realização.

\subsubsection{Goiás}

Em Goiás, foram observados cinco processos de dispensa de licitação durante a pesquisa. Dentre eles, apenas o processo $\mathrm{n}^{\mathrm{o}} 032 / 2020^{73}$ apresenta dois dos elementos básicos: a fundamentação legal (com base no art. 4 da Lei n 13.979/2020) e a análise circunstancial (sob argumentação de caráter emergencial na contratação em razão da Covid-19), não havendo, entretanto, a ponte entre o direito e a realidade. Portanto, essa justificativa foi classificada como insuficiente.

Quanto às fundamentações dos outros quatro processos ${ }^{74}$, percebe-se que apenas um dos elementos básicos foi detectado, a fundamentação legal. Logo, em razão da ausência dos demais elementos (análise circunstancial e ponte entre a realidade e o direito), as justificativas dispostas nas dispensas de licitação observadas são caracterizadas como insuficientes.

\subsubsection{Mato Grosso}

No estado do Mato Grosso foram observados cinco processos de dispensa de licitação, sendo possível identificar que quatro ${ }^{75}$ possuíam os três critérios

${ }^{72}$ GOVERNO DO DISTRITO FEDERAL. Secretaria de Saúde do Distrito Federal, 2020. Disponível em: <http://www.educacao.df.gov.br/dispensa-de-licitacao/> Acesso em 17 de agosto de 2020.

${ }^{73}$ GOIÁS. Processo 032/2020. Portal da Transparência. Prefeitura Municipal de Peixe Boi, 2020. Disponível em: <http://www.in.gov.br/web/dou/-/extratos-de-contratos-267102878>. Acesso em: 02 de agosto de 2020.

74 GOIÁS. Licitação 00077/2020. Portal da Transparência, 2020. Disponível em: $<$ http://www.portaltransparencia.gov.br/contratos/103707329?ordenarPor=descComplementarIte mCompra\&direcao=asc $>$. Acesso em: 02 de agosto de 2020; GOIÁS. Licitação 00015/2020. Portal da Transparência, 2020. Disponível em: $<$ http://www.portaltransparencia.gov.br/contratos/101007105?ordenarPor=descricao\&direcao=as c>. Acesso em: 02 de agosto de 2020; GOIÁS. Licitação 00002/2020. Portal da Transparência. Ministério da Saúde, 2020.2 Disponível $<$ http://www.portaltransparencia.gov.br/contratos/103007265? ordenarPor=descricao\&direcao=as c>. Acesso em: 02 de agosto de 2020; GOIÁS. Licitação 00575/2020. Portal da Transparência. Ministério da Educação, 2020. Disponível em: $<$ http://www.portaltransparencia.gov.br/contratos/97507493?ordenarPor=descricao\&direcao=asc >. Acesso em: 02 de agosto de 2020.

${ }^{75}$ MATO GROSSO. Termo de Referência 0015/2020. Assembleia Legislativa do Estado, 2020. Disponível em: <https://storage.al.mt.gov.br/api/v1/download/default/350917>. Acesso em: $02 \mathrm{de}$ agosto de 2020; MATO GROSSO. Termo de Referência 0021/2020. Assembleia Legislativa do Estado, 2020. Disponível em: <https://storage.al.mt.gov.br/api/v1/download/default/350961>. Acesso em: 02 de agosto de 2020; MATO GROSSO. Termo de Referência 0014/2020. Assembleia 
necessários: a fundamentação legal, a análise circunstancial e a ponte entre a lei e a realidade, portanto nos referidos processos constam os critérios mínimos, para que as justificativas possam ser classificadas como suficientes.

Além desses, o processo $n^{\circ}$ 0023/2020 ${ }^{76}$ apresentou apenas dois dos critérios considerados como necessários, sendo eles, a fundamentação legal (com base no art. 24, IV, 26, I a III da Lei 8.666/93) e a análise circunstancial (sob argumentação de situação emergencial no Estado e supervisão de saúde e qualidade de vida) não tendo sido desenvolvida uma relação entre ambos. Com isso, as justificativas são caracterizadas como insuficientes.

\subsubsection{Mato Grosso do Sul}

No Mato Grosso do Sul foram analisados quatro processos de dispensa de licitação. Dentre eles, apenas o processo $n^{\circ} 27 / 001.437 / 2020^{77}$ apresentou os três elementos básicos: a fundamentação legal, a análise circunstancial e a ponte entre o direito e a realidade. Portanto, essa justificativa se classifica como suficiente.

Cabe destacar que no processo $n^{\circ}$ 27/001.437/2020, que dispõe sobre a aquisição de materiais de higienização para atender a Agência Estadual de Administração do Sistema Penitenciário, a fundamentação legal teve por base o artigo 4-C da Lei 13.979/20. Na análise circunstancial, afirmou-se que, para enfrentar o estado de emergência de que trata esta lei, tornou-se desnecessária a elaboração de Estudo Técnico Preliminar. Também se argumentou que, ao ser declarado o surto de Coronavírus, surgiu a necessidade de contratação de materiais e insumos de prevenção de contágio, transmissão e manejo clínico dos casos diagnosticados.

Outros dois processos (Processo $n^{\circ}$ 27/001.216/2020 e Termo de Referência $n^{\circ}$ 0013/2020) apresentavam apenas dois critérios ${ }^{78}$ : a fundamentação legal e a análise circunstancial, contudo, não foi feita uma ponte entre a lei e a realidade, portanto não tendo sido completados os três requisitos básicos. Além desses, o processo n 31/950.007/2020 apresentou o elemento de fundamentação legal. Notadamente,

Legislativa do Estado, 2020. Disponível em: <https://storage.al.mt.gov.br/api/v1/download/default/350910>. Acesso em: 02 de agosto de 2020; MATO GROSSO. Termo de Referência 0013/2020. Assembleia Legislativa do Estado, 2020. Disponível em: <https://storage.al.mt.gov.br/api/v1/download/default/350904>. Acesso em: $02 \mathrm{de}$ agosto de 2020.

${ }^{76}$ MATO GROSSO. Termo de Referência 0023/2020. Assembleia Legislativa do Estado, 2020. Disponível em: <https://storage.al.mt.gov.br/api/v1/download/default/352183>. Acesso em: $02 \mathrm{de}$ agosto de 2020.

${ }_{77}$ MATO GROSSO DO SUL. Processo 27/001.437/2020. Portal da Transparência, 2020. Disponível em: <http://www.comprascoronavirus.ms.gov.br/detalhamento?autorizacao $=34457>$. Acesso em: 02 de agosto de 2020.

${ }^{78}$ MATO GROSSO DO SUL. Processo 27/001.216/2020. Portal da Transparência, 2020. Disponível em: <http://www.comprascoronavirus.ms.gov.br/detalhamento?autorizacao=34317>. Acesso em: 02 de agosto de 2020; MATO GROSSO DO SUL. Termo de Referência 0013/2020. Portal da Transparência, $2020 . \quad$ Disponível em: $<$ https://storage.al.mt.gov.br/api/v1/download/default/350904>. Acesso em: 02 de agosto de 2020. 
a ausência de diferentes elementos nos três mencionados processos, caracteriza suas justificativas como insuficientes.

\subsection{Sudeste}

\subsubsection{Espírito Santo}

No Estado do Espírito Santo, foram analisados cinco processos de dispensa de licitação. Em dois desses processos (Termo de Referência n ${ }^{\circ}$ 088/2020 e n085/2020) foram localizados os três elementos: fundamentação legal, análise circunstancial e ponte entre o direito e a realidade. Cabe destacar que ambos são provenientes da unidade LACEN/ Núcleo de Biologia Médica. Nas justificativas por eles apresentadas, a fundamentação legal tem por base o art. 24, IV da Lei nº 8.666/93; a análise circunstancial demonstra a necessidade de realização das compras pelas especificidades dos itens em questão que os tornam necessários para auxiliar na eficiência do combate à pandemia. Além desses elementos, os administradores responsáveis também construíram uma ponte entre a lei e a realidade, explicitando de que forma o momento atual se conecta com a previsão normativa. Logo, as justificativas se classificam como suficientes.

Nos demais processos, foram encontrados apenas dois elementos: fundamentação legal e análise circunstancial ${ }^{79}$, de forma que a ausência de correlação entre as normas jurídicas e a realidade fez essas justificativas serem classificadas como insuficientes. Nas fundamentações legais, os administradores tiveram por base o inciso IV, Art. 24 da Lei8.666/1993 e a Lei Complementar no $946 / 2020$. Nas análises circunstanciais foram explicitadas as razões pelas quais os itens pretendidos se tornam importantes no cenário de combate ao Coronavírus.

Cabe destacar que os processos dos órgãos Instituto de Atendimento Socioeducativo do Espírito Santo - IASES 80 e SSAFAS/SESA ${ }^{81}$ também

79 ESPÍRITO SANTO. Processo 2020-XJFDD. CORONAVÍRUS, 2020. Disponível em: $<$ https://coronavirus.es.gov.br/Media/Coronavirus/Transparencia/ContratosEmergenciais/072.\%2 0TR\%20Aquisi\%C3\%A7\%C3\%A3o\%20\%20Materiais\%20para\%20Preven\%C3\%A7\%C3\%A3o\%20 termometro\%20e\%20Oximetro_COVID\%2019_Keila...pdf> Acesso em: 22 de julho de 2020; ESPÍRITO SANTO. Termo de Referência 001/2020. CORONAVÍRUS, 2020. Disponível em: $<$ https://coronavirus.es.gov.br/Media/Coronavirus/Transparencia/ContratosEmergenciais/TR\%20 para\%20aquisi\%C3\%A7\%C3\%A3o\%20de\%20material\%20gr\%C3\%A1fico.pdf> Acesso em: 22 de julho de 2020; ESPÍRITO SANTO. Termo de Referência 033/2020. CORONAVÍRUS, 2020. Disponível $<$ https://coronavirus.es.gov.br/Media/Coronavirus/Transparencia/ContratosEmergenciais/2020206VK\%20-\%20TR.pdf> Acesso em: 22 de julho de 2020.

${ }^{80}$ GOVERNO DO ESTADO DO ESPÍRITO SANTO. Processo 2020-XJFDD. CORONAVÍRUS, 2020. Disponível

$<$ https://coronavirus.es.gov.br/Media/Coronavirus/Transparencia/ContratosEmergenciais/072.\%2 0TR\%20Aquisi\%C3\%A7\%C3\%A3o\%20\%20Materiais\%20para\%20Preven\%C3\%A7\%C3\%A3o\%20 termometro\%20e\%20Oximetro_COVID\%2019_Keila...pdf>Acesso em: 22 de julho de 2020.

81 GOVERNO DO ESTADO DO ESPÍRITO SANTO. Termo de Referência 033/2020. CORONAVÍRUS, 2020. 
apresentaram uma ponte entre a lei e a realidade, demonstrando como a situação em vigência se coloca nos termos previstos nas previsões normativas por eles destacadas configurando-se como uma circunstância extraordinária de possibilidade de dispensa de licitação. Essas justificativas foram classificadas como suficientes.

\subsubsection{Minas Gerais}

No Estado de Minas Gerais, foram analisados cinco processos de dispensa de licitação demandados pela Secretaria de Estado da Saúde ${ }^{82}$ e Polícia Militar do Estado de Minas Gerais ${ }^{83}$. Os processos encontram-se disponíveis no Portal da Transparência do Estado de Minas Gerais, contudo, dentre esse conjunto, não foram localizadas as justificativas de nenhum dos processos em questão. Em razão da falta de justificativa, os processos foram considerados insuficientes.

\subsubsection{Rio de Janeiro}

No Estado do Rio de Janeiro, foram analisados dez processos de dispensa de licitação ordenados pelas seguintes unidades: Secretaria de Estado de Planejamento

$<$ https://coronavirus.es.gov.br/Media/Coronavirus/Transparencia/ContratosEmergenciais/2020206VK\%20-\%20TR.pdf> Acesso em: 22 de julho de 2020.

82 GOVERNO DO ESTADO DE MINAS GERAIS. Processo de Compra 1501561000028/2020. PORTAL DA TRANSPARÊNCIA DO ESTADO DE MINAS GERAIS, 2020. Disponível em: $<$ http://www.transparencia.mg.gov.br/compras-e-patrimonio/compras-econtratos/comprasecontratos-procedimento/99/2020/01-01-2020/21-072020/1831017/2/0/0/42/65/104/6518/822/65181751/215727/1753681/323054/1501561000028-2020> Acesso em 22 de julho de 2020; GOVERNO DO ESTADO DE MINAS GERAIS. Processo de Compra 1501561000031/2020. PORTAL DA TRANSPARÊNCIA DO ESTADO DE MINAS GERAIS, 2020. Disponível em: <http://www.transparencia.mg.gov.br/compras-epatrimonio/compras-e-contratos/comprasecontratos-procedimento/99/2020/01-01-2020/21-072020/1831017/2/0/0/42/65/104/6518/822/65181751/219609/1758063/323435/1501561000031-2020>. Acesso em 22 de julho de 2020.

${ }^{83}$ GOVERNO DO ESTADO DE MINAS GERAIS. Processo de Compra 0250073000018/2020. PORTAL DA TRANSPARÊNCIA DO ESTADO DE MINAS GERAIS, 2020. Disponível em: $<$ http://www.transparencia.mg.gov.br/compras-e-patrimonio/compras-econtratos/comprasecontratos-procedimento/99/2020/01-01-2020/21-072020/1831094/2/0/0/42/65/104/6518/1068/65180461/181097/1700928/324944/0250073000018-2020> Acesso em 22 de julho de 2020; GOVERNO DO ESTADO DE MINAS GERAIS. Processo de Compra 0250073 000015/2020. PORTAL DA TRANSPARÊNCIA DO ESTADO DE MINAS GERAIS, 2020. Disponível em: <http://www.transparencia.mg.gov.br/compras-epatrimonio/compras-e-contratos/comprasecontratos-detalhe-

proccompra/2020/20200101/20201231/323974>. Acesso em 22 de julho de 2020; GOVERNO DO ESTADO DE MINAS GERAIS. Processo de Compra 0250073 000008/2020. PORTAL DA TRANSPARÊNCIA DO ESTADO DE MINAS GERAIS, 2020. Disponível em: $<$ http://www.transparencia.mg.gov.br/compras-e-patrimonio/compras-econtratos/comprasecontratos-detalhe-proccompra/2020/20200101/20201231/322626>. Acesso em 22 de julho de 2020. 
e Gestão (SEPLAG), Companhia de Desenvolvimento Rodoviário e Terminais do Estado do Rio de Janeiro (CODERTE), UERJ - Hospital Universitário Pedro Ernesto, Fundo Especial do Corpo de Bombeiros (FUNESBOM), Fundo Especial Polícia Militar (FUNESPOM), Secretaria de Estado da Administração Penitenciária, Secretaria de Estado de Agricultura, Pecuária, Abastecimento (SEAPA) e Fundo Estadual de Saúde.

Apenas uma compra direta (Processo de identificação SEI-270057/000652/2020) apresentou dois elementos básicos: fundamentação legal (com base no art. $4^{\circ}$ da Lei Federal n 13.979 de 2020) e, análise circunstancial, tendo por argumentação a necessidade de adquirir itens para o combate ao Coronavírus. ${ }^{84}$ Por prescindir da ponte entre realidade e direito, essa justificativa foi classificada como insuficiente. Todas as demais dispensas apresentaram apenas fundamentação legal ${ }^{85}$, portanto, também foram classificadas como insuficientes.

\subsubsection{São Paulo}

No Estado de São Paulo, foram analisados dez processos de dispensa de licitação ordenados pelos órgãos: Polícia Civil do Estado de São Paulo, Polícia Militar do Estado de São Paulo, Prodesp e Secretaria de Administração Penitenciária. Dentre esse conjunto, verificou-se que, até o momento de análise, três

${ }^{84}$ GOVERNO DO RIO DE JANEIRO. Processo SEI-270057/000652/2020. SISTEMA INTEGRADO DE GESTÃO DE AQUISIÇÕES. Disponível em: <https://www.compras.rj.gov.br/PortalSiga/CompraDireta/detalhar.action> Acesso em: 22 de julho de 2020.

${ }^{85}$ GOVERNO DO RIO DE JANEIRO. Processo SEI-120001/003346/2020. SISTEMA INTEGRADO DE GESTÃO DE AQUISIÇÕES. Disponível em: <https://www.compras.rj.gov.br/PortalSiga/CompraDireta/detalhar.action> Acesso em: 22 de julho de 2020; GOVERNO DO RIO DE JANEIRO. Processo E-26/008/1161/2020. SISTEMA INTEGRADO DE GESTÃO DE AQUISIÇÕES. Disponível em: <https://www.compras.rj.gov.br/Portal-Siga/CompraDireta/detalhar.action> Acesso em: 22 de julho de 2020; GOVERNO DO RIO DE JANEIRO. Processo E-26/008/1162/2020. SISTEMA INTEGRADO DE GESTÃO DE AQUISIÇÕES. Disponível em: <https://www.compras.rj.gov.br/Portal-Siga/CompraDireta/detalhar.action> Acesso em: 22 de julho de 2020; GOVERNO DO RIO DE JANEIRO. Processo SEI-210045/000077/2020. SISTEMA INTEGRADO DE GESTÃO DE AQUISIÇÕES. Disponível em: $<$ https://www.compras.rj.gov.br/Portal-Siga/CompraDireta/detalhar.action> Acesso em: 22 de julho de 2020; GOVERNO DO RIO DE JANEIRO. Processo SEI-080001/007014/2020. SISTEMA INTEGRADO DE GESTÃO DE AQUISIÇÕES. Disponível em: $<$ https://www.compras.rj.gov.br/Portal-Siga/CompraDireta/detalhar.action> Acesso em: 22 de julho de 2020; GOVERNO DO RIO DE JANEIRO. Processo SEI-120001/003222/2020. SISTEMA INTEGRADO DE GESTÃO DE AQUISIÇÕES. Disponível em: $<$ https://www.compras.rj.gov.br/Portal-Siga/CompraDireta/detalhar.action> Acesso em: 22 de julho de 2020; GOVERNO DO RIO DE JANEIRO. Processo SEI-120001/003222/2020. SISTEMA INTEGRADO DE GESTÃO DE AQUISIÇÕES. Disponível em: $<$ https://www.compras.rj.gov.br/Portal-Siga/CompraDireta/detalhar.action> Acesso em: 22 de julho de 2020. 
processos (PCSP-PRC-2020/00384, PCSPPRC202000385V01) não disponibilizaram nenhuma justificativa, classificando-se como insuficientes ${ }^{86}$.

O processo PMESPPRC202000150V01 ${ }^{87}$ apresentou apenas fundamentação legal, também sendo considerado insuficiente. Os processos PDPRC202001225V01 e PDPRC202001228V01 ${ }^{88}$ apresentaram somente análise circunstancial com base na necessidade de atendimentos às necessidades de suas respectivas unidades em decorrência do Coronavírus e se classificaram como insuficientes. Por fim, três processos (PMESPPRC202000385V01, SAPPRC202007044V01, SAPPRC202007366V01, SAPPRC202007677V01) ${ }^{89}$ apresentaram fundamentação legal e análise circunstancial. Contudo, considerando a ausência de correlação entre as normas jurídicas e a realidade que caracterizam o elemento de ponte entre o direito e a realidade, tiveram suas justificativas classificadas como insuficientes.

${ }^{86}$ GOVERNO DO ESTADO DE SÃO PAULO. Processo PCSP-PRC-2020/00384. SP CONTRA O NOVO CORONAVÍRUS, 2020. Disponível em: <https://www.saopaulo.sp.gov.br/guiacoronavirus/assets/docs-transparencia/PCSPPRC202000384V01.pdf >. Acesso em 21 de julho de 2020; GOVERNO DO ESTADO DE SÃO PAULO. Processo PCSP-PRC-2020/00385.SP. CONTRA O NOVO CORONAVÍRUS, 2020. Disponível em: <https://www.saopaulo.sp.gov.br/guiacoronavirus/assets/docs-transparencia/PCSPPRC202000385V01.pdf $>$ Acesso em 21 de julho de 2020; GOVERNO DO ESTADO DE SÃO PAULO. SP CONTRA O NOVO CORONAVÍRUS, 2020. Disponível em: <https://www.saopaulo.sp.gov.br/guia-coronavirus/assets/docstransparencia/PCSPPRC202000449V01.pdf>. Acesso em 21 de julho de 2020.

${ }^{87}$ GOVERNO DO ESTADO DE SÃO PAULO. Processo PMESP-PRC-2020/00150. SP CONTRA O NOVO CORONAVÍRUS, 2020. Disponível em: <https://www.saopaulo.sp.gov.br/guiacoronavirus/assets/docs-transparencia/PMESPPRC202000150V01.pdf $>$. Acesso em 21 de julho de 2020.

${ }^{88}$ GOVERNO DO ESTADO DE SÃO PAULO. Processo PD-PRC-2020/01225. SP CONTRA O NOVO CORONAVÍRUS, 2020. Disponível em: <https://www.saopaulo.sp.gov.br/guiacoronavirus/assets/docs-transparencia/PDPRC202001225V01.pdf $>$. Acesso em 21 de julho de 2020; GOVERNO DO ESTADO DE SÃO PAULO. Processo PD-PRC-2020/01228. SP CONTRA O NOVO CORONAVÍRUS, 2020. Disponível em: <https://www.saopaulo.sp.gov.br/guiacoronavirus/assets/docs-transparencia/PDPRC202001228V01.pdf> Acesso em 21 de julho de 2020.

${ }^{89}$ GOVERNO DO ESTADO DE SÃO PAULO. Processo PMESP-PRC-2020/00385. SP CONTRA O NOVO CORONAVÍRUS, 2020. Disponível em: <https://www.saopaulo.sp.gov.br/guiacoronavirus/assets/docs-transparencia/PMESPPRC202000385V01.pdf $>$. Acesso em 21 de julho de 2020; GOVERNO DO ESTADO DE SÃO PAULO. Processo SAP-PRC-2020/07044. SP CONTRA O NOVO CORONAVÍRUS, 2020. Disponível em: <https://www.saopaulo.sp.gov.br/guiacoronavirus/assets/docs-transparencia/SAPPRC202007044V01.pdf >. Acesso em 21 de julho de 2020; GOVERNO DO ESTADO DE SÃO PAULO. Processo SAP-PRC-2020/07366. SP CONTRA O NOVO CORONAVÍRUS, 2020. Disponível em: <https://www.saopaulo.sp.gov.br/guiacoronavirus/assets/docs-transparencia/SAPPRC202007366V01.pdf > Acesso em 21 de julho de 2020; GOVERNO DO ESTADO DE SÃO PAULO. Processo SAP-PRC-2020/07677. SP CONTRA O NOVO CORONAVÍRUS, 2020. Disponível em: <https://www.saopaulo.sp.gov.br/guiacoronavirus/assets/docs-transparencia/SAPPRC202007677V01.pdf > Acesso em 21 de julho de 2020. 


\subsection{Sul}

\subsubsection{Paraná}

No Paraná foram observados quatro processos de dispensa de licitação, sendo possível notar que três ${ }^{90}$ deles possuíam três elementos básicos: a fundamentação legal, a análise circunstancial e a ponte entre a lei e a realidade, portanto, apresentando os critérios mínimos necessários, para classificar as suas justificativas como suficientes.

Já no processo $016 / 2020^{91}$ foram encontrados somente dois elementos critérios: fundamentação legal (com base no artigo 4, 4-A ao 4- I, da Lei Federal 13.979/2020, artigo 35, § 4, incisos I, III, IV, V, VII, VIII, X ao XIII da Lei Estadual 15.608/2007 e no Decreto 4.319/2020) e análise circunstancial (fundamentada na necessidade de proteção da vida e saúde dos servidores e colaboradores do órgão em questão). Por prescindir do elemento de ponte entre a lei e a realidade, a justificativa desse processo foi considerada insuficiente.

\subsubsection{Rio Grande do Sul}

No Rio Grande do Sul foram identificados três processos de dispensa de licitação. Dentre eles, os processos 20/1300-0002711-9 e 20/1300-0002711-9 92 apresentaram os três elementos básicos: fundamentação legal, análise circunstancial e a ponte entre o direito e a realidade. Portanto, as justificativas de ambos os processos foram classificadas como suficientes.

\footnotetext{
${ }^{90}$ PARANÁ. Dispensa de Licitação 011/2020. Portal da Transparência. Diretoria Administrativa, 2020. Disponível em: $<$ http://transparencia.assembleia.pr.leg.br/storage/dispensas/LS9TDl3oVm86Mtj4kfdoAuhMyb5 DQKiJz70Qo8dr.pdf>. Acesso em: 02 de agosto de 2020; PARANÁ. Portal da Transparência. Assembleia Legislativa do Estado do Paraná, 2020. Disponível em: $<\mathrm{http}$ ://transparencia.assembleia.pr.leg.br/storage/dispensas/4AHanVOt6PLMPDPCAglrwMKhJ HKuMbCWurdLxSAT.pdf>. Acesso em: 02 de agosto de 2020; PARANÁ. Dispensa de Licitação 013/2020. Portal da Transparência. Assembleia Legislativa do Estado do Paraná, 2020. Disponível em:

$<$ http://transparencia.assembleia.pr.leg.br/storage/dispensas/53gihwhk8tL9BEFkWoVlCGmZ5V EbWGiF3oBoACvX.pdf $>$. Acesso em: 02 de agosto de 2020.

${ }^{91}$ PARANÁ. Processo Administrativo de Dispensa de Licitação 016/2020. Portal da Transparência. Assembleia Legislativa do Estado do Paraná, 2020. Disponível em: $<$ http://transparencia.assembleia.pr.leg.br/storage/dispensas/dsAx6HtA3VJz6L0PkhJrSBQkA1zw fqf6jWx6fBRI.pdf $>$. Acesso em: 02 de agosto de 2020.

${ }^{92}$ RIO GRANDE DO SUL. Processo 20/1300-0002711-9. Portal da Transparência, 2020. Disponível em: $<$ https://www.compras.rs.gov.br/anexos/507556d40106f56f3c24fae2f75643eca1ee7e7a08e60b45ab63499596c54dbe8765bb>. Acesso em: 02 de agosto de 2020; RIO GRANDE DO SUL. Processo 20/1300-0002711-9. Portal da Transparência, 2020. Disponível em: <https://www.compras.rs.gov.br/editais/0339_2020/260850>. Acesso em: 02 de agosto de 2020.
} 
Além destes, também se analisou o processo 20/1244-0014942-0 93 que apresentou apenas um dos elementos básicos: a fundamentação legal, tendo por argumentação a Lei Federal $n^{\circ}$ 13.979/2020. Conclui-se, portanto, que essa justificativa é insuficiente.

\subsubsection{Santa Catarina}

Em Santa Catarina foram analisados quatro processos de dispensa de licitação. Dentre eles, o processo licitatório 36/202094 apresentou dois dos elementos básicos: fundamentação legal (com base no Decreto 525, nos Decretos Municipais 37, 38, 39 e 40/2020, na Portaria no 188/GM/MS de 2020, no artigo 24, IV da Lei 8.666/93 e na Lei 13979 de 2020) e análise circunstancial (com fundamento na necessidade de assegurar condições adequadas aos usuários e profissionais da saúde). Além desse, foram observados outros três ${ }^{95}$ processos, nos quais apenas foi encontrado um dos elementos básicos: a fundamentação legal. Em razão da ausência dos demais elementos básicos, todas as justificativas analisadas no Estado se caracterizam como insuficientes.

\section{ANÁLISE}

Neste tópico, fazemos um balanço dos estados que tiveram mais justificativas classificadas como suficientes e dos que estão em situação mais "crônica", ou seja, que têm a maioria de suas fundamentações consideradas como insuficientes, segundo os critérios analisados na presente pesquisa.

${ }^{93}$ RIO GRANDE DO SUL. Processo 20/1244-0014942-0. Portal da Transparência, 2020. Disponível em: <https://www.compras.rs.gov.br/editais/0339_2020/260850\#documentsTab>. Acesso em: 02 de agosto de 2020.

${ }_{94}^{4}$ SANTA CATARINA. Processo licitatório 76/2020; Dispensa de licitação 14/2020. Estado de Santa Catarina Município de Antônio Carlos, 2020. Disponível em: $<$ http://edicao.dom.sc.gov.br/pdfjs/web/viewer.html?file=http\%3A\%2F\%2Fedicao.dom.sc.gov.br \%2F2020\%2F07\%2F1595002119_edicao_3203_assinada.pdf\#page=36>. Acesso em: 02 de agosto de 2020.

${ }^{95}$ SANTA CATARINA. Dispensa de licitação 3/COVID-19/PMI/2020. Diário Oficial da União. Prefeitura Municipal de Içara, 2020. Disponível em: <http://www.in.gov.br/web/dou/-/aviso-dedispensa-de-licitacao-n-3/covid-19/pmi/2020-261319295>. Acesso em: 02 de agosto de 2020; SANTA CATARINA. Aviso de dispensa de licitação 12/COVID-19/FMS/2020. Diário Oficial da União. Prefeitura Municipal de Içara, 2020. Disponível em: <http://www.in.gov.br/web/dou//aviso-de-dispensa-de-licitacao-n-12/covid-19/fms/2020-

261098263?inheritRedirect=true\&redirect=\%2Fweb\%2Fguest $\% 2$ Fsearch $\% 3 F q S e a r c h \% 3 D d i s p e n s a$ $\% 2520$ de $\% 2520$ licita $\% 25 \mathrm{C} 3 \% 25 \mathrm{~A} 7 \% 25 \mathrm{C} 3 \% 25 \mathrm{~A} 3 \mathrm{o} \% 2520$ covid $\% 2520$ santa $\% 2520$ catarina>. Acesso em: 02 de agosto de 2020; SANTA CATARINA. Processo Licitatório 070/2020 Dispensa de Licitação n⿳o 005/2020. Diário Oficial da União. Prefeitura Municipal de Porto União, 2020. Disponível em: <http://www.in.gov.br/web/dou/-/aviso-de-dispensa-de-licitacao252978274? inheritRedirect=true\&redirect $=\% 2 \mathrm{Fweb} \% 2 \mathrm{Fguest} \% 2 \mathrm{Fsearch} \% 3 \mathrm{FqSearch} \% 3$ Ddispensa $\% 2520$ de $\% 2520$ licita $\% 25 \mathrm{C} 3 \% 25 \mathrm{~A} 7 \% 25 \mathrm{C} 3 \% 25 \mathrm{~A} 3 \mathrm{o} \% 2520$ covid $\% 2520$ santa $\% 2520$ catarina>. Acesso em: 02 de agosto de 2020 . 
É importante ressaltar que este resultado não representa a "realidade" do Estado em relação a todas as suas licitações. Neste projeto de pesquisa, o conjunto de licitações examinado é restrito. Além disso, os processos de dispensa de licitação são ordenados por diferentes órgãos; portanto, as falhas não podem ser imputadas à administração de forma geral. Por sua vez, os dados provenientes desta pesquisa revelam que diversos processos de dispensa de licitação não obedecem aos critérios mínimos para que possam ser efetivamente controlados pela população ou até mesmo pelos tribunais.

Nesse sentido, deve-se relembrar que diversas contratações e aquisições realizadas durante a pandemia podem ser levadas aos órgãos de controle como o Tribunal de Contas ou o Poder Judiciário. No momento das contratações, tendo em vista necessidades imediatas e urgentes, o gestor se encontra em uma posição que exige celeridade. A urgência pode limitar realização de pesquisas de propostas profundas e economicamente benéficas. Para que tal situação seja conhecida pelo controlador, é decisivo que o administrador revele a realidade em na justificativa. Em última análise, a deficiência de justificação pode prejudicar o controle, resultando, em alguns casos, na punição ao próprio administrador.

Grande parte dos processos de dispensa de licitação observados na presente pesquisa tiveram em sua fundamentação apenas um dos elementos para justificação básica. E, portanto, as motivações apresentadas são insuficientes.

$\mathrm{Na}$ distribuição federativa, alguns Estados obtiveram, na maioria dos processos visualizados na presente pesquisa, justificativas consideradas suficientes: Acre, Rondônia, Mato Grosso, Paraná, Rio Grande do Sul. Já outros Estados, em grande parte dos processos examinados aqui, não providenciaram justificativa adequada de suas decisões: Pará, Roraima, Tocantins, Goiás, Santa Catarina, Alagoas, Bahia, Maranhão, Paraíba, Pernambuco, Rio Grande do Norte, Minas Gerais, Rio de Janeiro, São Paulo. 
Tabela 1 - Processo de Dispensa de Licitação - Usado na pesquisa para análise

\begin{tabular}{|c|c|c|c|}
\hline \multirow{2}{*}{ ESTADOS } & \multirow{2}{*}{ ANALISADOS } & \multicolumn{2}{|c|}{ JUSTIFICATIVAS } \\
\hline & & SUFICIENTE & INSUFICIENTE \\
\hline Acre & 07 & 04 & 03 \\
\hline Alagoas & 04 & - & 04 \\
\hline Amapá & 04 & 01 & 03 \\
\hline Amazonas & 06 & 02 & 04 \\
\hline Bahia & 06 & - & 06 \\
\hline Ceará & 05 & 01 & 04 \\
\hline Espírito Santo & 05 & 02 & 03 \\
\hline Goiás & 05 & - & 05 \\
\hline Maranhão & 04 & 01 & 03 \\
\hline Mato Grosso & 05 & 04 & 01 \\
\hline $\begin{array}{c}\text { Mato Grosso } \\
\text { do Sul }\end{array}$ & 04 & 01 & 03 \\
\hline Minas Gerais & 05 & - & 05 \\
\hline Pará & 06 & 02 & 04 \\
\hline Paraíba & 02 & - & 02 \\
\hline Paraná & 04 & 03 & 01 \\
\hline Pernambuco & 05 & - & 05 \\
\hline Piauí & 04 & 01 & 03 \\
\hline
\end{tabular}




\begin{tabular}{|c|c|c|c|}
\hline \multirow{2}{*}{ ESTADOS } & \multirow{2}{*}{ ANALISADOS } & \multicolumn{2}{|c|}{ JUSTIFICATIVAS } \\
\cline { 3 - 4 } & 02 & SUFICIENTE & INSUFICIENTE \\
\hline $\begin{array}{c}\text { Rio Grande do } \\
\text { Norte }\end{array}$ & 03 & 02 & 02 \\
\hline $\begin{array}{c}\text { Rio Grande do } \\
\text { Sul }\end{array}$ & 06 & - & 01 \\
\hline Rondônia & 04 & - & 02 \\
\hline Roraima & 04 & - & 04 \\
\hline Santa Catarina & 10 & - & 10 \\
\hline São Paulo & 04 & - & 04 \\
\hline Sergipe & 02 & - & 02 \\
\hline Tocantins & 01 & 01 & - \\
\hline Distrito Federal & & & 04 \\
\hline
\end{tabular}

Fonte: Pesquisa em sites do Governo Federal e Estadual

\section{CONCLUSÃo}

Os dados da pesquisa sugerem que, por trás de uma luta de excessos entre gestores e controladores, pode existir um problema ao mesmo tempo mais simples e mais complexo do que costumamos reconhecer: a incapacidade de parte da administração, ao menos durante a pandemia, em fundamentar suas decisões de dispensa licitatória com os elementos mínimos: sua base normativa, os fatos em particular e a ligação entre os pontos.

A carência de justificação das decisões administrativas ameaça criar uma distorção em sequência no funcionamento do estado e do direito. Ao receber um processo "sem motivação", resta ao controlador presumir que o gasto público ocorreu segundo o interesse público ou avançar, caso a caso, sobre as circunstâncias particulares de cada gasto. Se toma o primeiro caminho, arrisca "ratificar" uma decisão de gastos públicos sem que se comprovem, minimamente, os elementos formais básicos da dispensa licitatória. Se segue o segundo caminho, arrisca invadir desgovernadamente em zona típica de atuação do gestor público.

É neste cenário em que o país, no auge da pandemia, parece viver um "diálogo de surdos". Sem um "meio de campo" de interpretação e aplicação concreta do 
direito em cada caso, gestores e controladores dificilmente conseguirão se entender. As compras e aquisições aceleradas para atender à demanda emergencial da Covid19 "atrasam". O controle dos gastos, permitindo à população o conhecimento dos atos e diminuindo os espaços para vantagens indevidas, é dificultado.

Novas análises, com bases de dados mais abrangentes e fora do período de emergência, talvez auxiliem a compreender melhor a existência e escala do problema no país. E novas pesquisas, sobre a qualidade do controle exercido por Tribunais de Conta e pelo Ministério Público, podem igualmente revelar limites mais precisos da conduta destes órgãos no controle de gastos.

\section{REFERÊNCIAS}

ACRE. Portal de Transparência do Acre, 2020. Disponível em: $<$ http://app.tce.ac.gov.br/portaldaslicitacoes/paginas/publico/portal/processos/list as/dispensa/gerenciador.xhtml>. Acesso em: 02 de agosto de 2020.

ACRE. Portal de Transparência do Acre, 2020. Disponível em: $<$ http://app.tce.ac.gov.br/portaldaslicitacoes/paginas/publico/portal/processos/list as/dispensa/gerenciador.xhtml>. Acesso em: 02 de agosto de 2020.

ACRE. Portal de Transparência do Acre, 2020. Disponível em: $<$ http://app.tce.ac.gov.br/portaldaslicitacoes/paginas/publico/portal/processos/list as/dispensa/gerenciador.xhtml>. Acesso em: 02 de agosto de 2020.

ACRE. Portal de Transparência do Acre, 2020. Disponível em: $<$ http://app.tce.ac.gov.br/portaldaslicitacoes/paginas/publico/portal/processos/list as/dispensa/gerenciador.xhtml>. Acesso em: 02 de agosto de 2020.

ACRE. Portal de Transparência do Acre, 2020. Disponível em: $<$ http://app.tce.ac.gov.br/portaldaslicitacoes/paginas/publico/portal/processos/list as/dispensa/gerenciador.xhtml>. Acesso em: 02 de agosto de 2020.

ACRE. Portal de Transparência do Acre. Secretaria de Saúde do Estado, 2020. Disponível em:

$<$ http://app.tce.ac.gov.br/portaldaslicitacoes/paginas/publico/portal/processos/list as/dispensa/gerenciador.xhtml>. Acesso em: 02 de agosto de 2020

ACRE. Processo 19-20-005430. Portal de Transparência do Acre, 2020. Disponível em: <http://app.tce.ac.gov.br/portaldaslicitacoes/>. Acesso em: 02 de agosto de 2020 . 
ACRE. Processo 22/2020. Portal de Transparência do Acre, 2020. Disponível em: $<$ http://app.tce.ac.gov.br/portaldaslicitacoes/paginas/publico/portal/processos/list as/dispensa/gerenciador.xhtml . Acesso em: 02 de agosto de 2020.

ACRE. Processo 22/2020. Portal de Transparência do Acre, 2020. Disponível em: $<$ http://app.tce.ac.gov.br/portaldaslicitacoes/paginas/publico/portal/processos/list as/dispensa/gerenciador.xhtml>. Acesso em: 02 de agosto de 2020.

ALAGOAS. Processo E:52555.0000000785/2020. Portal Da Transparência Graciliano Ramos, 2020. Disponível em:

$<$ http://transparencia.al.gov.br/licitacao/contracoes-diretas/>. Acesso em 22 de julho de 2020.

AMAPÁ. Processo 004/2020. Centro de Reabilitação do Amapá, 2020. Disponível em: $<$ http://cosiga.ap.gov.br/covid/15769/anexo/justificativa_de_dispenca.pdf $>$. Acesso em: 02 de agosto de 2020.

AMAPÁ. Processo 006/2020. Superintendência de Vigilância em Saúde. Governo do Estado do Amapá, 2020. Disponível em:

$<$ http://cosiga.ap.gov.br/covid/15995/anexo/TERMO_DE_DISPENSA_DE_LICIT ACAO.pdf $>$. Acesso em: 02 de agosto de 2020.

AMAPÁ. Processo 300101.0005.0082.0330/2020. Coordenadoria de Gestão de Compras do Amapá. Secretaria de Saúde do Amapá, 2020. Disponível em: $<$ http://cosiga.ap.gov.br/covid/15681/anexo/TERMO_DE_DISPENSA_300101.0005. 0082.0330-2020.pdf $>$. Acesso em: 02 de agosto de 2020.

AMAPÁ. Processo 330101.2020.000027-SEJUSP e 00002/SEJUSP/2020. Secretaria do Estado de Saúde Pública, 2020. Disponível em:

$<$ http://cosiga.ap.gov.br/covid/16489/anexo/TERMO_04_-_E.P._DA_SILVA_paginas-1-3_-_assinado.pdf $>$. Acesso em: 02 de agosto de 2020.

AMAZONAS. Processo 011304.007528/2020. Portal da Transparência, 2020.

Disponível em: $<$ http://sistemas.sefaz.am.gov.br/sgcam/contratos.do?method=detalharContrato\&idContrato=21441>. Acesso em: 02 de agosto de 2020.

AMAZONAS. Processo 017101.010804/2020. Portal da Transparência. Unidade de Saúde do Estado do Amazonas, 2020. Disponível em:

$<$ http://sistemas.sefaz.am.gov.br/sgc-

am/contratos.do? method=detalharContrato\&idContrato=21487>. Acesso em: 02 de agosto de 2020. 
AMAZONAS. Processo 017101.010945/2020. Portal da Transparência, 2020. Disponível em: <http://sistemas.sefaz.am.gov.br/sgcam/contratos.do?method=detalharContrato\&idContrato=21409>. Acesso em: 02 de agosto de 2020.

AMAZONAS. Processo 017133.000150/2019. Portal da Transparência, 2020. Disponível em: <http://sistemas.sefaz.am.gov.br/sgc$\mathrm{am} /$ contratos.do? $\mathrm{method}=$ detalharContrato\&idContrato $=21450>$. Acesso em: 02 de agosto de 2020 .

AMAZONAS. Processo 017304.001022/2020. Portal da Transparência, 2020. Disponível em: $<$ https://www.ecompras.am.gov.br/publico/transparencia_licitacoes_detalhes.asp?ident=205533>. Acesso em: 02 de agosto de 2020.

AMAZONAS. Processo 017306.000830/2020. Portal da Transparência, 2020. Disponível em: <http://www.transparencia.am.gov.br/covid-19/licitacoes/>. Acesso em: 02 de agosto de 2020.

BRASIL. DECRETO 5.496 DE 2020. Disponível em:

<https://www.legisweb.com.br/legislacao/?id=394471>. Acesso em: 25 de agosto de 2020.

BRASIL. Decreto-Lei no. 4.657, de 1942, alterado pela Lei no. 13.655, de 2018.

BRASIL. Diário oficial da União, 2020. Disponível em:

$<$ https://www.in.gov.br/en/web/dou/-/portaria-n-424-de-22-de-junho-de-2020262970445>. Acesso em: 02 de agosto de 2020.

BRASIL. Lei 13.979 de 06 de fevereiro de 2020. Presidência da República Casa Civil, 2020. Disponível em:

<http://www.planalto.gov.br/ccivil_03/leis/18666cons.htm>. Acesso em: 01 de agosto de 2020 .

BRASIL. Lei 8.666 de 21 de junho de 1993. Presidência da República Casa Civil, 1993. Disponível em: <http://www.planalto.gov.br/ccivil_03/leis/18666cons.htm>. Acesso em: 01 de agosto de 2020.

BRASIL. Lei 9.789 de 29 de janeiro de 1999. Presidência da República Casa Civil, 1999. Disponível em: <http://www.planalto.gov.br/ccivil_03/leis/19784.htm>. Acesso em: 01 de agosto de 2020. 
BRASIL. Medida Provisória n 926, de 20 de março de 2020. Presidência da República Secretaria Geral Sub Chefia de Assuntos Jurídicos. Disponível em: <http://www.planalto.gov.br/ccivil_03/_ato2019-2022/2020/Mpv/mpv926.htm>. Acesso em: 01 de agosto de 2020.

BRASIL. Portaria ${ }^{\circ}$ 188/GM/MS, de 4 de fevereiro de 2020. Diário Oficial da União. Disponível em: < https://www.in.gov.br/en/web/dou/-/portaria-n-188-de-3de-fevereiro-de-2020-241408388>. Acesso em: 01 de agosto de 2020.

Diário Oficial do Municípios de Roraima, 20 de Maio de 2020. Processo ${ }^{\circ}$ 152/2020 - SMSA. Dispensa de Licitação n 025/2020 - CPL.

ESPÍRITO SANTO. Processo 2020-XJFDD. CORONAVÍRUS, 2020. Disponível em: $<$ https://coronavirus.es.gov.br/Media/Coronavirus/Transparencia/ContratosEmer genciais/072.\%20TR\%20Aquisi $\%$ C3\%A7\%C3\%A3o\%20\%20Materiais\%20para $\% 20$ Preven\%C3\%A7\%C3\%A3o\%20termometro\%20e\%20Oximetro_COVID\%2019_Kei la...pdf $>$ Acesso em: 22 de julho de 2020.

ESPÍRITO SANTO. Termo de Referência 001/2020. CORONAVÍRUS, 2020.

Disponível em:

$<$ https://coronavirus.es.gov.br/Media/Coronavirus/Transparencia/ContratosEmer genciais/TR\%20para\%20aquisi\%C3\%A7\%C3\%A3o\%20de\%20material\%20gr\%C3 \%A1fico.pdf> Acesso em: 22 de julho de 2020.

ESPÍRITO SANTO. Termo de Referência 033/2020. CORONAVÍRUS, 2020. Disponível em:

$<$ https://coronavirus.es.gov.br/Media/Coronavirus/Transparencia/ContratosEmer genciais/2020-206VK\%20-\%20TR.pdf> Acesso em: 22 de julho de 2020.

FILHO, Marçal Justen. Curso de Direito Administrativo. São Paulo: Editora Saraiva, 2005, p.309.

GOIÁS. Licitação 00002/2020. Portal da Transparência. Ministério da Saúde, 2020. Disponível em:

$<$ http://www.portaltransparencia.gov.br/contratos/103007265?ordenarPor=descric ao\&direcao=asc $>$. Acesso em: 02 de agosto de 2020.

GOIÁS. Licitação 00015/2020. Portal da Transparência, 2020. Disponível em: $<$ http://www.portaltransparencia.gov.br/contratos/101007105?ordenarPor=descric ao\&direcao=asc $>$. Acesso em: 02 de agosto de 2020. 
GOIÁS. Licitação 00077/2020. Portal da Transparência, 2020. Disponível em: $<$ http://www.portaltransparencia.gov.br/contratos/103707329?ordenarPor=descCo mplementarItemCompra\&direcao=asc $>$. Acesso em: 02 de agosto de 2020.

GOIÁS. Licitação 00575/2020. Portal da Transparência. Ministério da Educação, 2020. Disponível em:

$<$ http://www.portaltransparencia.gov.br/contratos/97507493?ordenarPor=descrica o\&direcao=asc $>$. Acesso em: 02 de agosto de 2020.

GOIÁS. Processo 032/2020. Portal da Transparência. Prefeitura Municipal de Peixe Boi, 2020. Disponível em: <http://www.in.gov.br/web/dou/-/extratos-de-contratos267102878>. Acesso em: 02 de agosto de 2020.

GOVERNO DO DISTRITO FEDERAL. Processo 04/2020. Secretaria de Saúde do Distrito Federal, 2020. Disponível em: <http://www.educacao.df.gov.br/wpconteudo/uploads/2017/11/Termo_de_Referencia_38389085.pdf> Acesso em 17 de agosto de 2020 .

GOVERNO DO DISTRITO FEDERAL. Secretaria de Saúde do Distrito Federal, 2020. Disponível em: <http://www.educacao.df.gov.br/dispensa-de-licitacao/> Acesso em 17 de agosto de 2020.

GOVERNO DO ESTADO DA BAHIA. Processo 019.5050.2020.0028421-02. SECRETARIA DA SAÚDE, 2020. Disponível em:

<http://www.saude.ba.gov.br/wp-content/uploads/2020/06/Dispensa-003-2020Cardioservice-AFM-19.004.00345-2020.pdf> Acesso em 22 de julho de 2020.

GOVERNO DO ESTADO DA BAHIA. Processo 019.7441.2020.0029397-61. SECRETARIA DA SAÚDE, 2020. Disponível em:

$<$ http://www.saude.ba.gov.br/wpcontent/uploads/2020/03/19.004.00330_2020.pdf> Acesso em 22 de julho de 2020.

GOVERNO DO ESTADO DA BAHIA. Processo 019.7441.2020.0029889-74. SECRETARIA DA SAÚDE, 2020. Disponível em: <http://www.saude.ba.gov.br/wp-content/uploads/2020/03/DRAGER162020.pdf> Acesso em 22 de julho de 2020.

GOVERNO DO ESTADO DA BAHIA. Processo 019.8634.2020.0035259-52. SECRETARIA DA SAÚDE, 2020. Disponível em: <http://www.saude.ba.gov.br/wp-content/uploads/2020/07/Contrato-N\%C2\%BA048.20-DE-008.20.pdf>. Acesso em 22 de julho de 2020. 
GOVERNO DO ESTADO DA BAHIA. Processo 019.8820.2020.006333-32.

SECRETARIA DA SAÚDE, 2020. Disponível em: <

http://www.saude.ba.gov.br/wp-content/uploads/2020/07/AFM-

19.123.00562_2020.pdf> Acesso em 22 de julho de 2020.

GOVERNO DO ESTADO DA BAHIA. Processo 019.9197.2020.0067967-76.

SECRETARIA DA SAÚDE, 2020. Disponível em: <

http://www.saude.ba.gov.br/wp-content/uploads/2020/07/AFM-704.2020.pdf>

Acesso em 22 de julho de 2020.

GOVERNO DO ESTADO DA PARAÍBA. Processo 23.901.000039.2020. PORTAL DA TRANSPARÊNCIA, 2020. Disponível em:

$<$ https://transparencia.pb.gov.br/coronavirus/?rpt=licitacoes_covid > Acesso em: 22 de julho de 2020.

GOVERNO DO ESTADO DA PARAÍBA. Processo 27.000.001668.2020. PORTAL DA TRANSPARÊNCIA, 2020. Disponível em:

$<$ https://transparencia.pb.gov.br/coronavirus/?rpt=licitacoes_covid $>$. Acesso em: 22 de julho de 2020.

GOVERNO DO ESTADO DE ALAGOAS. Processo e:01203.0000001068/2020.Portal da transparência graciliano ramos, 2020. Disponível em: <http://transparencia.al.gov.br/licitacao/contracoes-diretas/> Acesso em 22 de julho de 2020.

GOVERNO DO ESTADO DE MINAS GERAIS. Processo de Compra 0250073 000015/2020. PORTAL DA TRANSPARÊNCIA DO ESTADO DE MINAS GERAIS, 2020. Disponível em: <http://www.transparencia.mg.gov.br/compras-epatrimonio/compras-e-contratos/comprasecontratos-detalheproccompra/2020/20200101/20201231/323974>. Acesso em 22 de julho de 2020.

GOVERNO DO ESTADO DE MINAS GERAIS. Processo de Compra 0250073 000008/2020. PORTAL DA TRANSPARÊNCIA DO ESTADO DE MINAS GERAIS, 2020. Disponível em: <http://www.transparencia.mg.gov.br/compras-epatrimonio/compras-e-contratos/comprasecontratos-detalheproccompra/2020/20200101/20201231/322626>. Acesso em 22 de julho de 2020.

GOVERNO DO ESTADO DE MINAS GERAIS. Processo de Compra 0250073000018/2020. PORTAL DA TRANSPARÊNCIA DO ESTADO DE MINAS GERAIS, 2020. Disponível em: <http://www.transparencia.mg.gov.br/compras-epatrimonio/compras-e-contratos/comprasecontratos-procedimento/99/2020/01-012020/21-07- 
2020/1831094/2/0/0/42/65/104/6518/1068/65180461/181097/1700928/324944/0250073 000018-2020> Acesso em 22 de julho de 2020.

GOVERNO DO ESTADO DE MINAS GERAIS. Processo de Compra 1501561000028/2020. PORTAL DA TRANSPARÊNCIA DO ESTADO DE MINAS GERAIS, 2020. Disponível em: <http://www.transparencia.mg.gov.br/compras-epatrimonio/compras-e-contratos/comprasecontratos-procedimento/99/2020/01-012020/21-07-

2020/1831017/2/0/0/42/65/104/6518/822/65181751/215727/1753681/323054/15015610 00028-2020> Acesso em 22 de julho de 2020.

GOVERNO DO ESTADO DE MINAS GERAIS. Processo de Compra 1501561000031/2020. PORTAL DA TRANSPARÊNCIA DO ESTADO DE MINAS GERAIS, 2020. Disponível em: <http://www.transparencia.mg.gov.br/compras-epatrimonio/compras-e-contratos/comprasecontratos-procedimento/99/2020/01-012020/21-07-

2020/1831017/2/0/0/42/65/104/6518/822/65181751/219609/1758063/323435/15015610 00031-2020>. Acesso em 22 de julho de 2020.

GOVERNO DO ESTADO DE PERNAMBUCO. Processo 13575-5. PORTAL DA TRANSPARÊNCIA, 2020. Disponível em:

$<$ http://web.transparencia.pe.gov.br/despesas/despesas-detalhadas-covid-19/> Acesso em 22 de julho de 2020.

GOVERNO DO ESTADO DE PERNAMBUCO. Processo 383019-5. PORTAL DA TRANSPARÊNCIA, 2020. Disponível em: $<$ http://web.transparencia.pe.gov.br/despesas/despesas-detalhadas-covid-19/> Acesso em 22 de julho de 2020.

GOVERNO DO ESTADO DE PERNAMBUCO. Processo 512928-1. PORTAL DA TRANSPARÊNCIA, 2020. Disponível em:

$<$ http://web.transparencia.pe.gov.br/despesas/despesas-detalhadas-covid-19/>. Acesso em 22 de julho de 2020.

GOVERNO DO ESTADO DE PERNAMBUCO. Processo 513336-0. PORTAL DA TRANSPARÊNCIA, 2020. Disponível em:

$<$ http://web.transparencia.pe.gov.br/despesas/despesas-detalhadas-covid-19/> Acesso em 22 de julho de 2020.

GOVERNO DO ESTADO DE PERNAMBUCO. Processo 513713-6. PORTAL DA TRANSPARÊNCIA, 2020. Disponível em: < http://web.transparencia.pe.gov.br/despesas/despesas-detalhadas-covid-19/> Acesso em 22 de julho de 2020. 
GOVERNO DO ESTADO DE SÃO PAULO. Processo PCSP-PRC-2020/00384. SP CONTRA O NOVO CORONAVÍRUS, 2020. Disponível em: $<$ https://www.saopaulo.sp.gov.br/guia-coronavirus/assets/docstransparencia/PCSPPRC202000384V01.pdf $>$. Acesso em 21 de julho de 2020.

GOVERNO DO ESTADO DE SÃO PAULO. Processo PCSP-PRC-2020/00385.SP. CONTRA O NOVO CORONAVÍRUS, 2020. Disponível em: $<$ https://www.saopaulo.sp.gov.br/guia-coronavirus/assets/docstransparencia/PCSPPRC202000385V01.pdf> Acesso em 21 de julho de 2020.

GOVERNO DO ESTADO DE SÃO PAULO. Processo PD-PRC-2020/01225. SP CONTRA O NOVO CORONAVÍRUS, 2020. Disponível em: $<$ https://www.saopaulo.sp.gov.br/guia-coronavirus/assets/docstransparencia/PDPRC202001225V01.pdf >. Acesso em 21 de julho de 2020.

GOVERNO DO ESTADO DE SÃO PAULO. Processo PD-PRC-2020/01228. SP CONTRA O NOVO CORONAVÍRUS, 2020. Disponível em: $<$ https://www.saopaulo.sp.gov.br/guia-coronavirus/assets/docstransparencia/PDPRC202001228V01.pdf > Acesso em 21 de julho de 2020.

GOVERNO DO ESTADO DE SÃO PAULO. Processo PMESP-PRC-2020/00150. SP CONTRA O NOVO CORONAVÍRUS, 2020. Disponível em: $<$ https://www.saopaulo.sp.gov.br/guia-coronavirus/assets/docstransparencia/PMESPPRC202000150V01.pdf>. Acesso em 21 de julho de 2020.

GOVERNO DO ESTADO DE SÃO PAULO. Processo PMESP-PRC-2020/00385. SP CONTRA O NOVO CORONAVÍRUS, 2020. Disponível em: $<$ https://www.saopaulo.sp.gov.br/guia-coronavirus/assets/docstransparencia/PMESPPRC202000385V01.pdf $>$. Acesso em 21 de julho de 2020.

GOVERNO DO ESTADO DE SÃO PAULO. Processo SAP-PRC-2020/07044. SP CONTRA O NOVO CORONAVÍRUS, 2020. Disponível em: $<$ https://www.saopaulo.sp.gov.br/guia-coronavirus/assets/docstransparencia/SAPPRC202007044V01.pdf>. Acesso em 21 de julho de 2020.

GOVERNO DO ESTADO DE SÃO PAULO. Processo SAP-PRC-2020/07366. SP CONTRA O NOVO CORONAVÍRUS, 2020. Disponível em: $<$ https://www.saopaulo.sp.gov.br/guia-coronavirus/assets/docstransparencia/SAPPRC202007366V01.pdf> Acesso em 21 de julho de 2020.

GOVERNO DO ESTADO DE SÃO PAULO. Processo SAP-PRC-2020/07677. SP CONTRA O NOVO CORONAVÍRUS, 2020. Disponível em: 
<https://www.saopaulo.sp.gov.br/guia-coronavirus/assets/docstransparencia/SAPPRC202007677V01.pdf> Acesso em 21 de julho de 2020.

\section{GOVERNO DO ESTADO DE SÃO PAULO. SP CONTRA O NOVO}

CORONAVÍRUS, 2020. Disponível em: <https://www.saopaulo.sp.gov.br/guiacoronavirus/assets/docs-transparencia/PCSPPRC202000449V01.pdf $>$. Acesso em 21 de julho de 2020.

GOVERNO DO ESTADO DE SERGIPE. Processo 020.000.05173/2020-8. TODOS CONTRA O CORONA, 2020. Disponível em:

<https://todoscontraocorona.net.br/wp-content/uploads/2020/07/DL-224.2020.pdf> Acesso em 22 de julho de 2020.

GOVERNO DO ESTADO DE SERGIPE. Processo 020.000.06333/2020-0. TODOS CONTRA O CORONA, 2020. Disponível em:

$<$ https://todoscontraocorona.net.br/wp-content/uploads/2020/07/DL-

240.2020.pdf $>$. Acesso em 22 de julho de 2020.

GOVERNO DO ESTADO DE SERGIPE. Processo 020.000.06335/2020-1. TODOS CONTRA O CORONA, 2020. Disponível em:

$<$ https://todoscontraocorona.net.br/wp-content/uploads/2020/07/DL-

278.2020.pdf $>$. Acesso em 22 de julho de 2020.

GOVERNO DO ESTADO DE SERGIPE. Processo 04.292.445/0001-43. TODOS CONTRA O CORONA, 2020. Disponível em: $<$ https://todoscontraocorona.net.br/wp-content/uploads/2020/07/DL278.2020.pdf $>$. Acesso em 22 de julho de 2020.

GOVERNO DO ESTADO DO CEARÁ. Processo 006.30.03.2020. TRIBUNAL DE CONTAS DO ESTADO DO CEARÁ, 2020. Disponível em:

$<$ https://licitacoes.tce.ce.gov.br/index.php/dispensa_inexibilidade/detalhes/proc/1 58133/licit/25032> Acesso em 22 de julho de 2020.

GOVERNO DO ESTADO DO CEARÁ. Processo 118794/2020. TRIBUNAL DE CONTAS DO ESTADO DO CEARÁ, 2020. Disponível em:

$<$ https://icitacoes.tce.ce.gov.br/index.php/dispensa_inexibilidade/detalhes/proc/1 57947/licit/24955> Acesso em 22 de julho de 2020.

GOVERNO DO ESTADO DO CEARÁ. Processo 119834/2020. TRIBUNAL DE CONTAS DO ESTADO DO CEARÁ, 2020. Disponível em:

$<$ https://icitacoes.tce.ce.gov.br/index.php/dispensa_inexibilidade/detalhes/proc/1 57854/licit/24917> Acesso em 22 de julho de 2020. 
GOVERNO DO ESTADO DO CEARÁ. Processo 3103.01/2020/2020. TRIBUNAL DE CONTAS DO ESTADO DO CEARÁ, 2020. Disponível em:<https://icitacoes.tce.ce.gov.br/index.php/dispensa_inexibilidade/detalhes/pro c/157271/licit/24720 > Acesso em 22 de julho de 2020.

\section{GOVERNO DO ESTADO DO CEARÁ. TRIBUNAL DE CONTAS DO ESTADO} DO CEARÁ, 2020. Disponível em:

$<$ https://icitacoes.tce.ce.gov.br/index.php/dispensa_inexibilidade/detalhes/proc/1 57535/licit/24820> Acesso em 21 de julho de 2020.

GOVERNO DO ESTADO DO ESPÍRITO SANTO. Processo 2020-XJFDD. CORONAVÍRUS, 2020. Disponível em:

$<$ https://coronavirus.es.gov.br/Media/Coronavirus/Transparencia/ContratosEmer genciais/072.\%20TR\%20Aquisi\%C3\%A7\%C3\%A3o\%20\%20Materiais\%20para $\% 20$ Preven\%C3\%A7\%C3\%A3o\%20termometro\%20e\%20Oximetro_COVID\%2019_Kei la...pdf $>$ Acesso em: 22 de julho de 2020.

GOVERNO DO ESTADO DO ESPÍRITO SANTO. Termo de Referência 033/2020. CORONAVÍRUS, 2020. Disponível em: $<$ https://coronavirus.es.gov.br/Media/Coronavirus/Transparencia/ContratosEmer genciais/2020-206VK\%20-\%20TR.pdf> Acesso em: 22 de julho de 2020.

GOVERNO DO ESTADO DO MARANHÃO. Processo 61883/2020. SECID, 2020. Disponível em: <https://secid.ma.gov.br/files/2020/04/Ratifica\%C3\%A7\%C3\%A3ode-Dispensa-n\%C2\%BA-003.2020.pdf> Acesso em 22 de julho de 2020.

GOVERNO DO ESTADO DO MARANHÃO. Processo 68383/2020. SECID, 2020. Disponível em: <

https://secid.ma.gov.br/files/2020/06/Ratifica\%C3\%A7\%C3\%A3o-Dispensan\%C2\%BA-006.2020.pdf>. Acesso em 22 de julho de 2020.

GOVERNO DO ESTADO DO MARANHÃO. TRIBUNAL DE CONTAS DO ESTADO DO MARANHÃO, 2020. Processo de Dispensa $N^{\circ}$ 008/2020. Disponível em: $<$ https://www6.tce.ma.gov.br/sacop/muralsite/muralcovid.zul > Acesso em 25 de agosto de 2020.

GOVERNO DO ESTADO DO MARANHÃO. TRIBUNAL DE CONTAS DO ESTADO DO MARANHÃO, 2020. Processo de Dispensa $N^{\circ}$ 022/2020. Disponível em: <https://www6.tce.ma.gov.br/sacop/muralsite/muralcovid.zul> Acesso em 25 de agosto de 2020.

GOVERNO DO ESTADO DO PIAUÍ. Controle TCE: LW-003316/20. Tribunal de Contas do Estado do Piauí, 2020. Disponível em: 
<https://sistemas.tce.pi.gov.br/muralic/detalhelicitacao.xhtml?id=352685> Acesso em: 17 de agosto de 2020.

GOVERNO DO ESTADO DO PIAUÍ. Controle TCE: LW-003406/20. Tribunal de Contas do Estado do Piauí, 2020. Disponível em:

$<$ https://sistemas.tce.pi.gov.br/muralic/detalhelicitacao.xhtml?id=352785> Acesso em: 17 de agosto de 2020.

GOVERNO DO ESTADO DO PIAUÍ. Controle TCE: LW-003412/20. Tribunal de Contas do Estado do Piauí, 2020. Disponível em:

$<$ https://sistemas.tce.pi.gov.br/muralic/detalhelicitacao.xhtml?id=352791 > Acesso em: 17 de agosto de 2020.

GOVERNO DO ESTADO DO PIAUÍ. Controle TCE: LW-003613/20. Tribunal de Contas do Estado do Piauí, 2020. Disponível em:

$<$ https://sistemas.tce.pi.gov.br/muralic/detalhelicitacao.xhtml?id=353055> Acesso em: 17 de agosto de 2020.

GOVERNO DO ESTADO DO RIO GRANDE DO NORTE. PORTAL DA TRANSPARÊNCIA, 2020. Disponível em:

$<$ http://transparencia.rn.gov.br/docs/comprasservicos/ContratosCOVID19/Contrato-n20.00698CAERN.pdf > Acesso em 25 de agosto de 2020.

GOVERNO DO RIO DE JANEIRO. Processo E-26/008/1161/2020. SISTEMA INTEGRADO DE GESTÃO DE AQUISIÇÕES. Disponível em:

$<$ https://www.compras.rj.gov.br/Portal-Siga/CompraDireta/detalhar.action> Acesso em: 22 de julho de 2020.

GOVERNO DO RIO DE JANEIRO. Processo E-26/008/1162/2020. SISTEMA INTEGRADO DE GESTÃO DE AQUISIÇÕES. Disponível em: $<$ https://www.compras.rj.gov.br/Portal-Siga/CompraDireta/detalhar.action> Acesso em: 22 de julho de 2020.

GOVERNO DO RIO DE JANEIRO. Processo SEI-080001/007014/2020. SISTEMA INTEGRADO DE GESTÃO DE AQUISIÇÕES. Disponível em: $<$ https://www.compras.rj.gov.br/Portal-Siga/CompraDireta/detalhar.action> Acesso em: 22 de julho de 2020.

GOVERNO DO RIO DE JANEIRO. Processo SEI-120001/003222/2020. SISTEMA INTEGRADO DE GESTÃO DE AQUISIÇÕES. Disponível em: 
$<$ https://www.compras.rj.gov.br/Portal-Siga/CompraDireta/detalhar.action> Acesso em: 22 de julho de 2020.

GOVERNO DO RIO DE JANEIRO. Processo SEI-120001/003222/2020. SISTEMA INTEGRADO DE GESTÃO DE AQUISIÇÕES. Disponível em: $<$ https://www.compras.rj.gov.br/Portal-Siga/CompraDireta/detalhar.action> Acesso em: 22 de julho de 2020.

GOVERNO DO RIO DE JANEIRO. Processo SEI-120001/003346/2020. SISTEMA INTEGRADO DE GESTÃO DE AQUISIÇÕES. Disponível em: $<$ https://www.compras.rj.gov.br/Portal-Siga/CompraDireta/detalhar.action> Acesso em: 22 de julho de 2020.

GOVERNO DO RIO DE JANEIRO. Processo SEI-210045/000077/2020. SISTEMA INTEGRADO DE GESTÃO DE AQUISIÇÕES. Disponível em: $<$ https://www.compras.rj.gov.br/Portal-Siga/CompraDireta/detalhar.action> Acesso em: 22 de julho de 2020.

GOVERNO DO RIO DE JANEIRO. Processo SEI-270057/000652/2020. SISTEMA INTEGRADO DE GESTÃO DE AQUISIÇÕES. Disponível em: $<$ https://www.compras.rj.gov.br/Portal-Siga/CompraDireta/detalhar.action> Acesso em: 22 de julho de 2020.

MATO GROSSO DO SUL. Processo 27/001.216/2020. Portal da Transparência, 2020. Disponível em:

$<$ http://www.comprascoronavirus.ms.gov.br/detalhamento?autorizacao=34317> . Acesso em: 02 de agosto de 2020.

MATO GROSSO DO SUL. Processo 27/001.437/2020. Portal da Transparência, 2020. Disponível em: $<\mathrm{http} / / /$ www.comprascoronavirus.ms.gov.br/detalhamento?autorizacao=34457>. Acesso em: 02 de agosto de 2020.

MATO GROSSO DO SUL. Termo de Referência 0013/2020. Portal da Transparência, 2020. Disponível em:

$<$ https://storage.al.mt.gov.br/api/v1/download/default/350904>. Acesso em: 02 de agosto de 2020.

MATO GROSSO. Termo de Referência 0013/2020. Assembleia Legislativa do Estado, 2020. Disponível em:

$<$ https://storage.al.mt.gov.br/api/v1/download/default/350904>. Acesso em: 02 de agosto de 2020. 
MATO GROSSO. Termo de Referência 0014/2020. Assembleia Legislativa do Estado, 2020. Disponível em:

$<$ https://storage.al.mt.gov.br/api/v1/download/default/350910>. Acesso em: 02 de agosto de 2020 .

MATO GROSSO. Termo de Referência 0015/2020. Assembleia Legislativa do Estado, 2020. Disponível em:

<https://storage.al.mt.gov.br/api/v1/download/default/350917>. Acesso em: 02 de agosto de 2020 .

MATO GROSSO. Termo de Referência 0021/2020. Assembleia Legislativa do Estado, 2020. Disponível em:

<https://storage.al.mt.gov.br/api/v1/download/default/350961>. Acesso em: 02 de agosto de 2020.

MATO GROSSO. Termo de Referência 0023/2020. Assembleia Legislativa do Estado, 2020. Disponível em:

$<$ https://storage.al.mt.gov.br/api/v1/download/default/352183>. Acesso em: 02 de agosto de 2020 .

MINISTÉRIO PÚBLICO DO RIO DE JANEIRO. MPRJ realiza operação em investigação sobre contratos de aquisição de respiradores em meio à pandemia do novo coronavírus, 2020. Disponível em: <https://www.mprj.mp.br/home//detalhe-noticia/visualizar/84918> Acesso em: 06 de outubro de 2020.

PARÁ. Processo 01606001/20. Tribunal de contas dos Municípios do Estado do Pará, 2020. Disponível em: <https://www.tcm.pa.gov.br/mural-delicitacoes/licitacoes/ficha/QT6FIMNpWU55UU>. Acesso em: 02 de agosto de 2020.

PARÁ. Processo 4/2020. Tribunal de contas dos Municípios do Estado do Pará, 2020. Disponível em: <https://www.tcm.pa.gov.br/mural-de-

licitacoes/licitacoes/ficha/QT6FIMNpWQ51UU>. Acesso em: 02 de agosto de 2020.

PARÁ. Processo 632/2020. Tribunal de contas dos Municípios do Estado do Pará. Prefeitura Municipal de Afuá, 2020. Disponível em: $<$ https://www.tcm.pa.gov.br/mural-delicitacoes/licitacoes/ficha/QT6FIMNpWU14UQ>. Acesso em: 02 de agosto de 2020. 
PARÁ. Processo 7/2020-2905001. Tribunal de contas dos Municípios do Estado do Pará, 2020. Disponível em: <https://www.tcm.pa.gov.br/mural-de-

licitacoes/licitacoes/ficha/QT6FIMNRVS65UQ>. Acesso em: 02 de agosto de 2020.

PARÁ. Processo 733/2020. Tribunal de contas dos Municípios do Estado do Pará. Prefeitura Municipal de Afuá, 2020. Disponível em:

$<$ https://www.tcm.pa.gov.br/mural-de-

licitacoes/licitacoes/ficha/QT6FIMNpWVx40Z>. Acesso em: 02 de agosto de 2020.

PARÁ. Processo 837/2020. Tribunal de contas dos Municípios do Estado do Pará, 2020. Disponível em: $<$ https://www.tcm.pa.gov.br/mural-de-

licitacoes/licitacoes/ficha/QT6FIMNp2a310d\#licitacao>. Acesso em: 02 de agosto de 2020.

PARANÁ. Dispensa de Licitação 011/2020. Portal da Transparência. Diretoria Administrativa, 2020. Disponível em:

$<\mathrm{http}$ ://transparencia.assembleia.pr.leg.br/storage/dispensas/LS9TDl3oVm86Mtj4 kfdoAuhMyb5DQKiJz70Qo8dr.pdf $>$. Acesso em: 02 de agosto de 2020.

PARANÁ. Dispensa de Licitação 013/2020. Portal da Transparência. Assembleia Legislativa do Estado do Paraná, 2020. Disponível em:

$<$ http://transparencia.assembleia.pr.leg.br/storage/dispensas/53gihwhk8tL9BEFk WoVlCGmZ5VEbWGiF3oBoACvX.pdf>. Acesso em: 02 de agosto de 2020.

PARANÁ. Portal da Transparência. Assembleia Legislativa do Estado do Paraná, 2020. Disponível em:

$<$ http://transparencia.assembleia.pr.leg.br/storage/dispensas/4AHanVOt6PLMPD PCAglrwMKhJHKuMbCWurdLxSAT.pdf >. Acesso em: 02 de agosto de 2020.

PARANÁ. Processo Administrativo de Dispensa de Licitação 016/2020. Portal da Transparência. Assembleia Legislativa do Estado do Paraná, 2020. Disponível em: $<$ http://transparencia.assembleia.pr.leg.br/storage/dispensas/dsAx6HtA3VJz6L0P khJrSBQkA1zwfqf6jWx6fBRI.pdf>. Acesso em: 02 de agosto de 2020.

\section{POLÍCIA FEDERAL. MINISTÉRIO DA JUSTIÇA E SEGURANÇA PÚBLICA.}

Polícia Federal deflagra Operação Para Bellum e investiga compra de respiradores no Pará, 2020. Disponível em: <http://www.pf.gov.br/imprensa/noticias/2020/06noticias-de-junho-de-2020/policia-federal-deflagra-operacao-para-bellum-einvestiga-compra-de-respiradores-no-para> Acesso em: 06 de outubro de 2020.

REPÚBLICA FEDERATIVA DO BRASIL. DL 04.2020. Universidade Federal do Alagoas, 2020. Disponível em: <https://ufal.br/transparencia/licitacoes/dispensa- 
de-licitacao/2020/justificativa-dl-04-2020.pdf/view> Acesso em 21 de julho de 2020.

REPÚBLICA FEDERATIVA DO BRASIL. IMPRENSA NACIONAL, 2020.

Disponível em: <https://www.in.gov.br/web/dou/-/aviso-de-dispensa-de-licitacaon-7/2020-251930859> Acesso em 22 de julho de 2020.

REPÚBLICA FEDERATIVA DO BRASIL. Processo 23540.005668/2020-93. Hospitais Universitários Federais, Ministério da Educação, 2020. Disponível em: $<$ http://www2.ebserh.gov.br/documents/221436/5033452/26.03+Dispensas+de+Lici ta\%C3\%A7\%C3\%A3o+para+o+Combate+ao+COVID-19++ATUALIZADA+EM+26-05-2020.pdf/afa7fa38-0f7b-4dee-9be9-c10e7050651a> Acesso em 21 de julho de 2020.

RIO GRANDE DO SUL. Processo 20/1244-0014942-0. Portal da Transparência, 2020. Disponível em:

<https://www.compras.rs.gov.br/editais/0339_2020/260850\#documentsTab>. Acesso em: 02 de agosto de 2020.

RIO GRANDE DO SUL. Processo 20/1300-0002711-9. Portal da Transparência, 2020. Disponível em: <https://www.compras.rs.gov.br/anexos/507556d40106f56f3c24fae2f75643eca1ee7e7a08e60b45ab63499596c54dbe8765bb>. Acesso em: 02 de agosto de 2020.

RIO GRANDE DO SUL. Processo 20/1300-0002711-9. Portal da Transparência, 2020. Disponível em: <https://www.compras.rs.gov.br/editais/0339_2020/260850>. Acesso em: 02 de agosto de 2020.

RONDÔNIA. Portal da Transparência. Secretaria de Estado da Saúde, 2020. Disponível em:

$<$ http://www.transparencia.ro.gov.br/Arquivo/VisualizarArquivo?pEncArquivoId =7YPL9zi61ZjpXAm9Bv2JLqdzNQFFmRfccEVfG6rXONYsNQF_LUNODd4Mj55pplbL1MhTARF7k_13P6zDECpiWUbXk5z-CPS4ttIC5mnzY3QU4L>. Acesso em: 02 de agosto de 2020.

RONDÔNIA. Portal da Transparência. Secretaria de Estado da Saúde, 2020. Disponível em:

$<$ http://www.transparencia.ro.gov.br/Arquivo/VisualizarArquivo?pEncArquivoId $=\mathrm{jH} 9 \mathrm{afHbH}$ 9ROQ5a0LD_9U-

Q5mAlT9bcJeUqJ05s4kzq0BPsMz2Rvzy_TVohNq0z5XJq70z1Ifw4VtTJULv0R62AEWMgQoEERxrfRM8Q9qCk3QU4L>. Acesso em: 02 de agosto de 2020. 
RONDÔNIA. Portal da Transparência. Superintendência Estadual de Compras e Licitações, 2020. Disponível em:

$<$ http://www.transparencia.ro.gov.br/Arquivo/VisualizarArquivo?pEncArquivoId $=4$ _YN_vi_ym3dPn_ZELVkCYkrXDklCNpFWk3AMQmAtv119hNwGMNrNMor Y9QuIbf-iQxjtKVK00ahxzP8qtuuKHiIq30LkYEHlxxKbnhMubc3QU4L>. Acesso em: 02 de agosto de 2020.

RONDÔNIA. Processo: 0036.237367/2020-21. Portal da Transparência. Secretaria de Estado da Saúde, 2020. Disponível em:

$<$ http://www.transparencia.ro.gov.br/Arquivo/VisualizarArquivo?pEncArquivoId $=$ hl7Uz-K6DJX0fR3lvTg87_95pcq_tVqSVrTEotZ3HRgWz4t4VwCcbE0qsmMSYr1qV3q_sMsPqbafyoNxnuqZj4nRPN_58zJ2hqvePjGsD03QU4L>. Acesso em: 02 de agosto de 2020.

RORAIMA. Processo $n^{\circ}$ 117/2020. Diário Oficial da União. Prefeitura Municipal de São João da Baliza, 2020. Disponível em: <https://www.in.gov.br/en/web/dou//extrato-de-dispensa-de-licitacao-

258736342? inheritRedirect=true\&redirect=\%2Fweb\%2Fguest $\% 2 \mathrm{Fsearch} \% 3 \mathrm{FqSearc}$ h\%3DDispensa\%2520de\%2520licita\%25C3\%25A7\%25C3\%25A3o\%2520roraima>. Acesso em: 02 de agosto de 2020.

RORAIMA. Processo no 013/2020. Diário Oficial da União. Prefeitura Municipal de Amajari, 2020. Disponível em: <https://www.in.gov.br/en/web/dou/-/aviso-dedispensa-de-licitacao-

256322117? inheritRedirect=true\&redirect=\%2Fweb\%2Fguest $\% 2 \mathrm{Fsearch} \% 3 \mathrm{FqSearc}$ h\%3DDispensa\%2520de\%2520licita\%25C3\%25A7\%25C3\%25A3o\%2520roraima>. Acesso em: 02 de agosto de 2020.

RORAIMA. Processo no 082/2020. Diário Oficial da União. Prefeitura Municipal de Rorainópolis, 2020. Disponível em: <https://www.in.gov.br/en/web/dou//aviso-de-dispensa-de-licitacao-260834961>. Acesso em: 02 de agosto de 2020.

SANTA CATARINA. Aviso de dispensa de licitação 12/COVID-19/FMS/2020. Diário Oficial da União. Prefeitura Municipal de Içara, 2020. Disponível em: $<$ http://www.in.gov.br/web/dou/-/aviso-de-dispensa-de-licitacao-n-12/covid$19 / \mathrm{fms} / 2020-$

261098263? inheritRedirect=true\&redirect=\%2Fweb\%2Fguest $\% 2 \mathrm{Fsearch} \% 3 \mathrm{FqSearc}$ h\%3Ddispensa\%2520de \%2520licita\%25C3\%25A7\%25C3\%25A3o\%2520covid $\% 252$ 0santa\%2520catarina>. Acesso em: 02 de agosto de 2020.

SANTA CATARINA. Dispensa de licitação 3/COVID-19/PMI/2020. Diário Oficial da União. Prefeitura Municipal de Içara, 2020. Disponível em: 
<http://www.in.gov.br/web/dou/-/aviso-de-dispensa-de-licitacao-n-3/covid19/pmi/2020-261319295>. Acesso em: 02 de agosto de 2020.

SANTA CATARINA. Processo Licitatório 070/2020 Dispensa de Licitação no 005/2020. Diário Oficial da União. Prefeitura Municipal de Porto União, 2020. Disponível em: <http://www.in.gov.br/web/dou/-/aviso-de-dispensa-de-licitacao252978274? inheritRedirect $=$ true\&redirect $=\% 2 \mathrm{Fweb} \% 2 \mathrm{Fguest} \% 2 \mathrm{Fsearch} \% 3 \mathrm{FqSearc}$ h\%3Ddispensa\%2520de\%2520licita \%25C3\%25A7\%25C3\%25A3o\%2520covid $\% 252$ 0santa\%2520catarina>. Acesso em: 02 de agosto de 2020.

SANTA CATARINA. Processo licitatório 76/2020; Dispensa de licitação 14/2020. Estado de Santa Catarina Município de Antônio Carlos, 2020. Disponível em: $<$ http://edicao.dom.sc.gov.br/pdfjs/web/viewer.html?file=http\%3A\%2F\%2Fedicao. dom.sc.gov.br\%2F2020\%2F07\%2F1595002119_edicao_3203_assinada.pdf\#page=36 >. Acesso em: 02 de agosto de 2020.

TOCANTINS. Licitação 00005/2020. Portal da Transparência. Ministério da Educação, 2020. Disponível em:

$<$ http://www.portaltransparencia.gov.br/contratos/96207404?ordenarPor=descrica o\&direcao=asc\#termoBuscaPortal $>$. Acesso em: 02 de agosto de 2020.

TOCANTINS. Licitação 00077/2020. Portal da Transparência. Ministério da Defesa, 2020. Disponível em:

<http://www.portaltransparencia.gov.br/contratos/103707329?ordenarPor=descric ao\&direcao=asc $>$. Acesso em: 02 de agosto de 2020. 